\title{
Polyvinyl Alcohol Fiber Length Optimization for High Ductility Cementitious Composites with Different Compressive Strength Grades
}

\author{
Ding Cong, ${ }^{1,2}$ Guo Liping $\mathbb{D}^{3,4}$ Ren Jinming, ${ }^{1}$ Wang Yongming, ${ }^{1}$ Li Xinyu, ${ }^{1}$ Yu Bing, \\ Gao Yuan, ${ }^{1,}$ and Liu Wanpeng ${ }^{1}$ \\ ${ }^{1}$ POWERCHINA HUADONG Engineering Corporation Limited, Hangzhou 310000, China \\ ${ }^{2}$ School of Materials Science and Engineering, Tongji University, Shanghai 201800, China \\ ${ }^{3}$ Jiangsu Key Laboratory of Construction Materials, Collaborative Innovation Center for Advanced Civil Engineering Materials, \\ Nanjing 211189, China \\ ${ }^{4}$ School of Materials Science and Engineering, Southeast University, Nanjing 211189, China
}

Correspondence should be addressed to Guo Liping; guoliping691@163.com

Received 4 August 2021; Revised 9 October 2021; Accepted 26 October 2021; Published 2 December 2021

Academic Editor: Shazim A. Memon

Copyright $\odot 2021$ Ding Cong et al. This is an open access article distributed under the Creative Commons Attribution License, which permits unrestricted use, distribution, and reproduction in any medium, provided the original work is properly cited.

\begin{abstract}
The fiber length has a significant impact on the fiber bridging capacity and the mechanical properties of high ductility cementitious composites (HDCCs), which is related to fiber/matrix interfacial bonding. However, this fundamental knowledge of HDCCs design has rarely been investigated systematically. To this end, this study deeply investigates the effect of the fiber length on the bridging stress and the complementary energy with various fiber/matrix interfacial bonds in theory. Then, the mechanical performances of HDCCs with various fiber lengths and compressive strengths were evaluated experimentally. In micromechanical design, longer fibers can achieve stronger bridging stress and more sufficient complementary energy regardless of the fiber/matrix interfacial bonding properties. However, it should be noted that the increase in bridging capacity was quite slow for the overlong fibers and excessive interfacial bonding. The experiments indicated that overlong fibers (18 mm and $24 \mathrm{~mm}$ ) easily twined on the mixer blade and were hard to disperse evenly. The HDCCs with shorter fibers displayed better workability. The compressive strength was less affected by the fiber length, and most striking differences were less than $5.0 \%$, while the flexural properties and the tensile properties first increased and then decreased when the fiber length ranged from $6 \mathrm{~mm}$ to $24 \mathrm{~mm}$. Consequently, the fibers with lengths of $9 \mathrm{~mm}$ and the fibers with lengths of $12 \mathrm{~mm}$ were better candidates for the HDCCs with compressive strengths of $30 \mathrm{MPa}$ to $80 \mathrm{MPa}$, and fibers with lengths of $9 \mathrm{~mm}$ caused the HDCCs to exhibit higher ductility properties in general.
\end{abstract}

\section{Introduction}

High ductility cementitious composites (HDCCs) are a special kind of civil engineering materials that have attracted increasing interest in recent years due to their high tensile strain and robust strain hardening behaviour. Moreover, the excellent crack control ability of HDCCs features the characteristics of multiple cracks rather than a localized crack, and the typical crack width is generally less than $100 \mu \mathrm{m}$ [1-5]. The unique mechanical properties of HDCCs materials overcome the weaknesses in the inherent brittleness and cracking sensitivity of traditional concrete. Hence, broad application prospects can be expected in civil infrastructures where the structures are resilient, durable, and sustainable $[6,7]$. In typical HDCCs, high strength and high modulus polyvinyl alcohol (PVA) fibers have been widely employed because of their reasonable price and strong crack-bridging capacity [8]. Currently, PVA-HDCCs with compressive strengths ranging from $30 \mathrm{MPa}$ to $80 \mathrm{MPa}$ have been widely developed to meet various engineering requirements [9-11]. To improve the mechanical performances of HDCCs, the study of tailored micromechanical 
parameters has always been a key research focus. Since the micromechanical bridging theory was introduced by Li et al., it has been a significant tool to guide the material design of HDCCs, which covers the fibers, matrix, and fiber/matrix interface $[12,13]$. Currently, many researchers focus on tailoring the HDCCs matrix and fiber/matrix interface bond to obtain high tensile ductility or tensile strength. However, few researchers have focused on the tailoring of fiber parameters (tensile strength, elastic modulus, length, and diameter). The tensile strength and elastic modulus of fibers are inherent properties that hardly change and depend on the material characteristics and production technology. In contrast, the fiber length can be easily customized and controlled [14], and it is advisable to tailor the fiber length to develop the full potential of fiber performance and maximize the fiber bridging effect.

The fiber length has a profound impact on the mode of failure and resulting strain capacity of a composite. In general, fibers with a longer length can provide a greater embedment length, and a stronger stress would be needed to achieve fiber debonding and slipping from the matrix [12]. If the fiber length is shorter, the fiber stress will be extremely weak, where the stress is far less than the maximum stress that the fiber can be afforded, and a large number of performance margins will not be utilized. In contrast, if the fiber length is long, the fiber stress will be larger than the fiber strength, the fiber will be more prone to rupture, and the ruptured fiber will no longer bridge cracks during propagation [12]. In addition, it is difficult to easily disperse long fibers. In either case, the inferior ductility and the absence of strain hardening behaviour will occur due to incorrect selection of fiber length [15]. Therefore, an optimization of fiber length has great significance for HDCCs design. Figure 1 summarizes the PVA fiber length and diameter adopted in 83 related studies, and typical references can be found in [16-28]. PVA fibers with moderate lengths of $8 \mathrm{~mm}$ and $12 \mathrm{~mm}$ were universally employed in HDCCs, even though a length of $12 \mathrm{~mm}$ has become a universally accepted length. However, it is unclear which of these two fiber lengths should be selected in HDCCs design or whether shorter or longer fibers are a better candidate to achieve superior characteristics of HDCCs. In addition, whether the appropriate fiber length is related to the matrix properties has not been explored deeply.

Based on the analysis of micromechanical models, Maalej and $\mathrm{Li}[12,14]$ proposed that the optimum fiber length depends on the fiber diameter, fiber strength, and fiber/matrix interfacial bonding strength, beyond which an increase in the fiber length slightly increases the tensile strength but significantly reduces the fracture energy. Additionally, the optimum fiber length decreases with increasing fiber/matrix bonding strength. Lu et al. [29] proposed that the PVA fiber with $12 \mathrm{~mm}$ can make the HDCCs exhibit the best ductility by means of theoretical calculation. Although the longer fibers were more likely to rupture, the ultimate tensile strength of HDCCs tended to be higher. Georgiou et al. [30] presented that the use of longer fibers can improve the tensile strength and strain capacity. Furthermore, the mechanical performance of the composites with $12 \mathrm{~mm}$ fibers was noticeably better than that of the composites with $8 \mathrm{~mm}$ fibers. Sasmal et al. [31] investigated the flexural properties of HDCCs with $8 \mathrm{~mm}$ and $12 \mathrm{~mm}$ fibers, while they concluded that the variation in the fiber length from $8 \mathrm{~mm}$ to $12 \mathrm{~mm}$ did not induce any significant improvement in the flexural strength and even showed a slight decrease of $2.0 \%$ in the volume fraction, which was distinctly different from the conclusions obtained by Dai et al. [32] who used polyethylene (PE) fiber $(6 \mathrm{~mm}, 12 \mathrm{~mm}$ and $18 \mathrm{~mm}$ ) and seawater sea-sand to prepare HDCCs; they found that the fiber length had no obvious effect on the compressive strength. Longer fiber length had no obvious effect on the tensile strength but led to a significant increase in the tensile strain capacity, from $2.5 \%$ for $6 \mathrm{~mm}$ fiber to over $7 \%$ for $18 \mathrm{~mm}$ fiber. Yilmaz et al. [33] investigated the effect of polypropylene (PP) fiber length $(6,12$, and $18 \mathrm{~mm})$ on strength behaviour of fiber-reinforced cementitious composites. Results showed that the longer fiber length does not necessarily lead to the higher unconfined compressive strength of samples, but the integrity of the sample under the same external load is better. In view of the above conflicting conclusions, it is still necessary to further investigate the effect of the fiber length on the fiber bridging capacity and mechanical performance of HDCCs. In addition, the effect of fiber length is still unclear for the HDCCs with different strength grade.

Accordingly, this paper made an in-depth study on the influence of fiber length on fiber bridging capacity and HDCCs properties by combining experimental and theoretical method. The purpose was conducted to tailor the PVA fiber length to achieve better mechanical performance of HDCCs. To this end, PVA fibers with lengths of $6 \mathrm{~mm}$, $9 \mathrm{~mm}, 12 \mathrm{~mm}, 18 \mathrm{~mm}$, and $24 \mathrm{~mm}$ were used, and HDCCs with diverse compressive strengths ranging from $30 \mathrm{MPa}$ to $80 \mathrm{MPa}$ were prepared. On the one hand, a systematic result regarding the effect of the fiber length can be achieved by employing shorter/moderate/longer fiber lengths. On the other hand, the strength grades for the PVA-HDCCs are typical, as discussed before. In the present work, the compressive strength, four-point flexural properties, and uniaxial tensile properties of HDCCs were investigated, and then an appropriate fiber length was determined by this series of experiments. In addition, the micromechanical mechanism was elaborated based on the fiber bridging theory. Curves of the fiber bridging stress versus the crack opening length for different fiber lengths and interfacial bonding strengths were drawn, and the effects on the fiber bridging stress $\sigma_{0}$ and the complement energy $J_{b}^{\prime}$ were summarized to guide the selection of fiber parameters.

\section{Micromechanical Theoretical Mechanism of the Affected Bridging Capacity}

The fiber bridging micromechanical theory describes the relationship between the bridging stress $\sigma$ and the crack opening width $\delta$ (Figure 2), which links the micromechanical properties (matrix, fiber, matrix/fiber interface property, etc.) to the composite properties (tensile strength, tensile ductility, crack width, etc.) [34]. The fiber bridging 


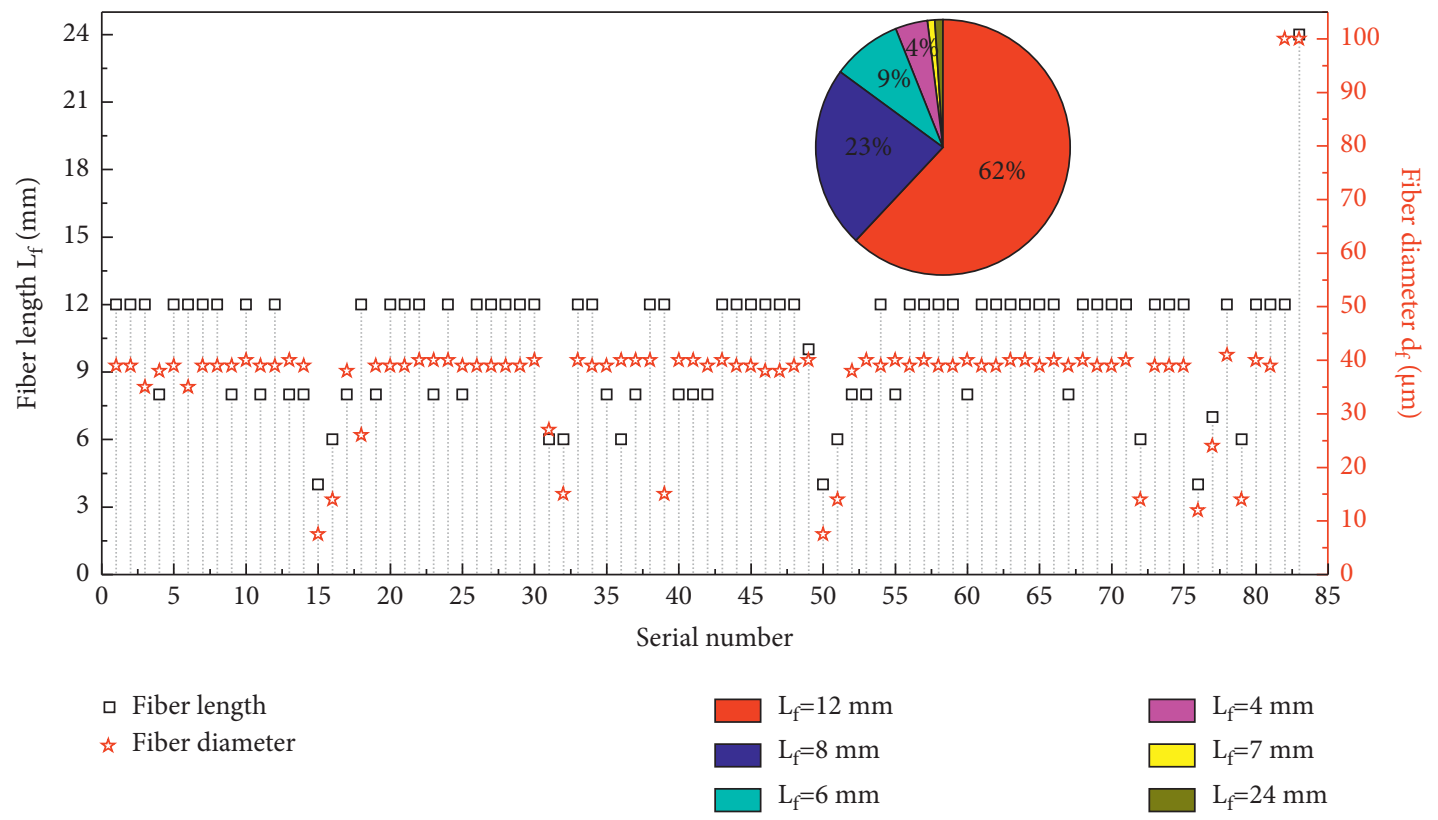

Figure 1: Adopted PVA fiber lengths and diameters in related research [16-28].

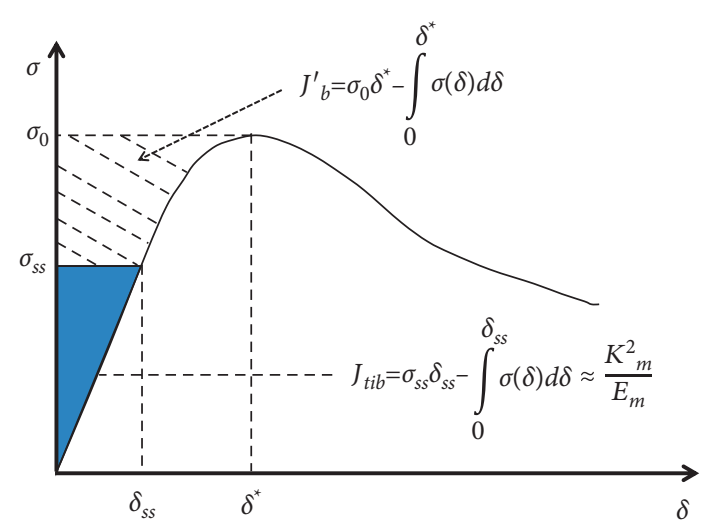

FIGURE 2: Relationship between crack opening $\delta$ and fiber bridging stress $\sigma$ [34].

capacity can be characterized by the fiber bridging stress $\sigma_{0}$ and the complementary energy $J_{b}^{\prime}$, as shown in Figure 2 [34]. A detailed introduction to the micromechanical theoretical can be seen in [34].

To attain sufficient strain hardening behaviour and prevent the formation of multiple cracks in HDCCs, the strength criterion $\left(\sigma_{0} \geq \sigma_{c r}\right)$ and energy criterion $\left(J_{b}^{\prime} \geq J_{\text {tip }}\right)$ need to be satisfied synchronously [34]. The strength criterion requires that the fiber bridging stress $\sigma_{0}$ exceeds the initial cracking strength $\sigma_{c r}$, which is the prerequisite for steady-state cracking. The energy criterion requires that the complementary energy $J_{b}^{\prime}$ exceeds the crack tip toughness $J_{\text {tip }}$, which provides an adequate energy supply for multiple saturated cracks $[35,36]$. The failure to meet these two key criteria will result in the Griffith cracking pattern being valid for an unrestricted crack width when the crack is extended [37, 38]. For the micromechanical design of HDCCs, pseudo-strain hardening (PSH) indexes
$\left(\mathrm{PSH}_{\mathrm{S}}=\sigma_{0} / \sigma_{c r}\right.$ and $\left.\mathrm{PSH}_{\mathrm{E}}=J_{b}^{\prime} / J_{\text {tip }}\right)$ were proposed to ensure multiple saturated cracks and robust tensile strain hardening [39]. Therefore, an appropriate fiber length should make the bridging capacity achieve the fundamental requirements of PSH indexes.

In essence, the excellent performances of HDCCs are derived from the sufficient bridging capacity of fibers. Ideally, longer fibers have greater fiber bridging capacity, whereas the fibers will rupture during the bridging process once the fiber stress exceeds the fiber tensile strength. The fiber rupture zone is illustrated in Figure 3, and detailed descriptions about the critical rupture length can be found in the literature [13]. The fiber rupture effect is caused by a large fiber embedment length or excessive fiber/matrix interfacial bonding. Generally, a longer fiber can provide a larger embedment length, and a higher-strength matrix will result in stronger fiber/matrix interfacial bonding; hence, the fiber rupture effect will be significant. Ruptured fibers can no longer bridge cracks, and then the bridging stress $\sigma_{0}$ and the complementary energy $J_{b}^{\prime}$ will experience losses [40], as shown in Figure 4. The fiber ruptured effect weakens the fiber bridging capacity $\left(\sigma_{0}, J_{b}^{\prime}\right)$. Different fiber length and fiber/matrix interfacial bonding can cause different degrees of fiber rupture, and its effect on fiber bridging capacity will also be significantly different. The detailed analysis will be given in the following.

To intuitively demonstrate the effect of the fiber length combined with fiber/matrix interfacial bonding, Figure 5 shows the affected fiber rupture zone, and Figure 6 draws the fiber bridging stress $\sigma$ versus crack opening $\delta$ curves for fiber lengths $L_{f}$ ranging from $3 \mathrm{~mm}$ to $24 \mathrm{~mm}$ and fiber/matrix interfacial bonding strengths $\tau_{0}$ ranging from $1.0 \mathrm{MPa}$ to 8.0 MPa. The selected ranges for the fiber length $L_{f}$ and fiber/matrix interfacial bonding strength $\tau_{0}$ cover the main values in related research. 


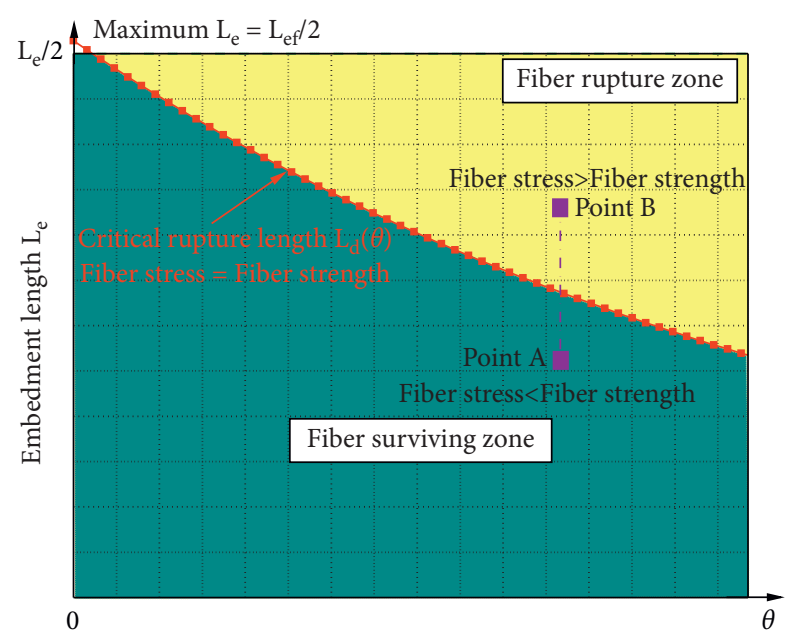

Inclined angle $\theta$

Figure 3: Diagram of the fiber rupture zone.

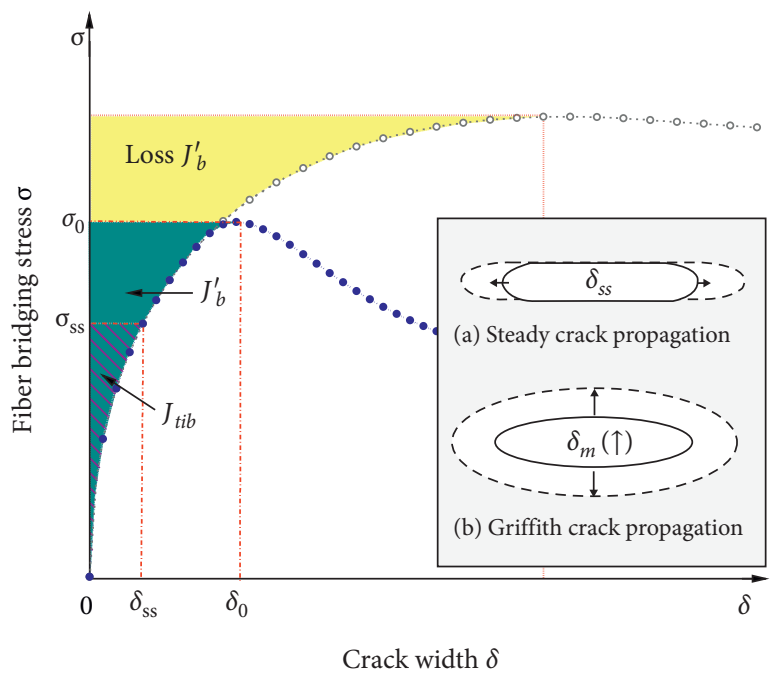

$\multimap \sigma(\delta)$ relation without considering fiber ruptured effect

- $\sigma(\delta)$ relation with considering fiber ruptured effect

$\square$ Loss $J^{\prime}{ }_{b}$

$\square J^{\prime}{ }_{b}$

U. $J_{\text {tib }}$

FIgURE 4: Fiber bridging stress with/without the fiber rupture.

As shown in Figure 5, the fibers have no rupture or a lower rupture proportion when the fiber/matrix interfacial bonding is weak. For example, the minimal critical rupture length reaches $5.3 \mathrm{~mm}$ when $\tau_{0}=1.0 \mathrm{MPa}$, which means that fibers with lengths less than $10.6 \mathrm{~mm}$ will survive. With the increase in interfacial bonding $\tau_{0}$, the critical rupture length decreases. The fiber rupture effect will occur as long as the fiber length exceeds $1.34 \mathrm{~mm}$ when $\tau_{0}=8.0 \mathrm{MPa}$, and the rupture proportion of fibers is considerable. As a result, Figure 6(a) shows that the $\sigma$ - $\delta$ curves are gentle, and the fiber bridging stress $\sigma_{0}$ rapidly increases with the fiber length. With the increase in fiber/matrix interfacial bonding $\tau_{0}$, the

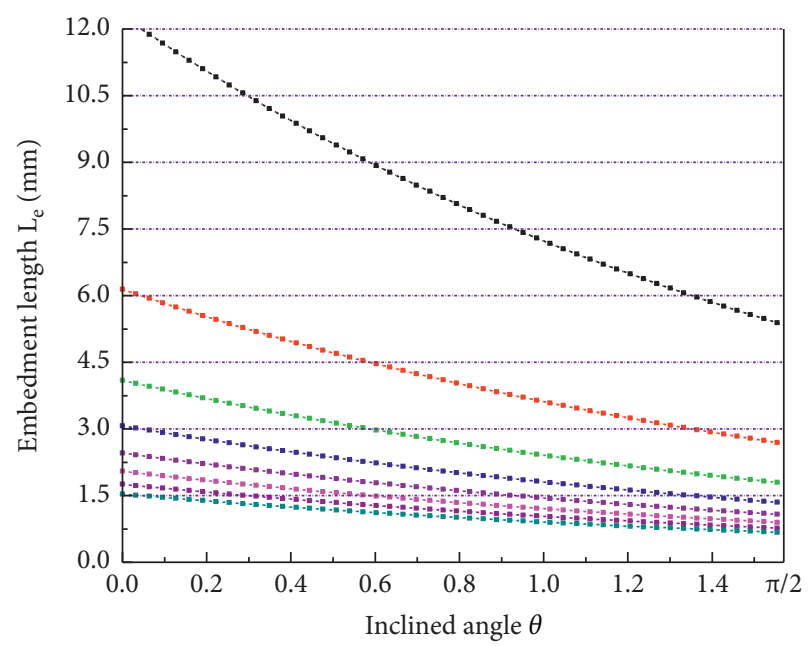

Critical rupture length $\mathrm{L}_{\mathrm{d}}(\theta)$

$$
\begin{aligned}
& \ldots \tau_{0}=1 \mathrm{MPa} \quad \ldots \ldots \tau_{0}=5 \mathrm{MPa} \\
& \text {..... } \tau_{0}=2 \mathrm{MPa} \quad \ldots \ldots \tau_{0}=6 \mathrm{MPa} \\
& \text { … } \tau_{0}=3 \mathrm{MPa} \tau_{0}=7 \mathrm{MPa} \\
& \text {.... } \tau_{0}=4 \mathrm{MPa} \quad \ldots \ldots \tau_{0}=8 \mathrm{MPa}
\end{aligned}
$$

FIgURE 5: Rupture zone with interfacial bonding from $1 \mathrm{MPa}$ to $8 \mathrm{MPa}$.

fiber rupture effect is more critical, and the fiber bridging stress drops rapidly and is accompanied by a tighter cracking opening $\delta_{0}$ after reaching the ultimate point; hence, the $\sigma-\delta$ curves become sharp. Furthermore, there are no significant differences in the fiber bridging capacity for the longer fibers, as illustrated in Figure 6(h).

The contour profiles of the fiber bridging stress $\sigma_{0}$ and the complementary energy $J_{b}^{\prime}$ are presented in Figure 7 . The detailed bridging model can be found in [40] and will not be described here. Figure 7 demonstrates the effects of the fiber length $L_{f}$ and the interfacial bonding $\tau_{0}$ on the fiber bridging stress $\sigma_{0}$ and the complementary energy $J_{b}^{\prime}$.

As shown in Figure 7(a), longer fibers can achieve a stronger bridging stress $\sigma_{0}$ even if fiber rupture occurs, but it should be noted that the increase in the bridging stress $\sigma_{0}$ is actually very slow when the fiber length exceeds $12 \mathrm{~mm}$. Figure 7 (b) exhibits a similar effect on the complementary energy $J_{b}^{\prime}$. Moreover, for weaker interfacial bonding $\tau_{0}$, the effects of the fiber length on the bridging stress $\sigma_{0}$ and the complementary energy $J_{b}^{\prime}$ are more significant than that of higher interfacial bonding $\tau_{0}$. With the increase in interfacial bonding $\tau_{0}$, the bridging stresses $\sigma_{0}$ are enhanced for fibers with lengths of $6 \mathrm{~mm}$ to $24 \mathrm{~mm}$, while the complementary energy values $J_{b}^{\prime}$ increase first and then decrease for the fibers with lengths of $6 \mathrm{~mm}, 9 \mathrm{~mm}$, and $12 \mathrm{~mm}$, and the values continue to decrease for fibers with lengths of $18 \mathrm{~mm}$ and $24 \mathrm{~mm}$.

Based on the requirements of the strength criterion and energy criterion, a higher bridging stress and complementary energy can achieve better mechanical performance for HDCCs. Theoretical analyses indicate that longer fibers can perform better than shorter fibers. However, it should be 

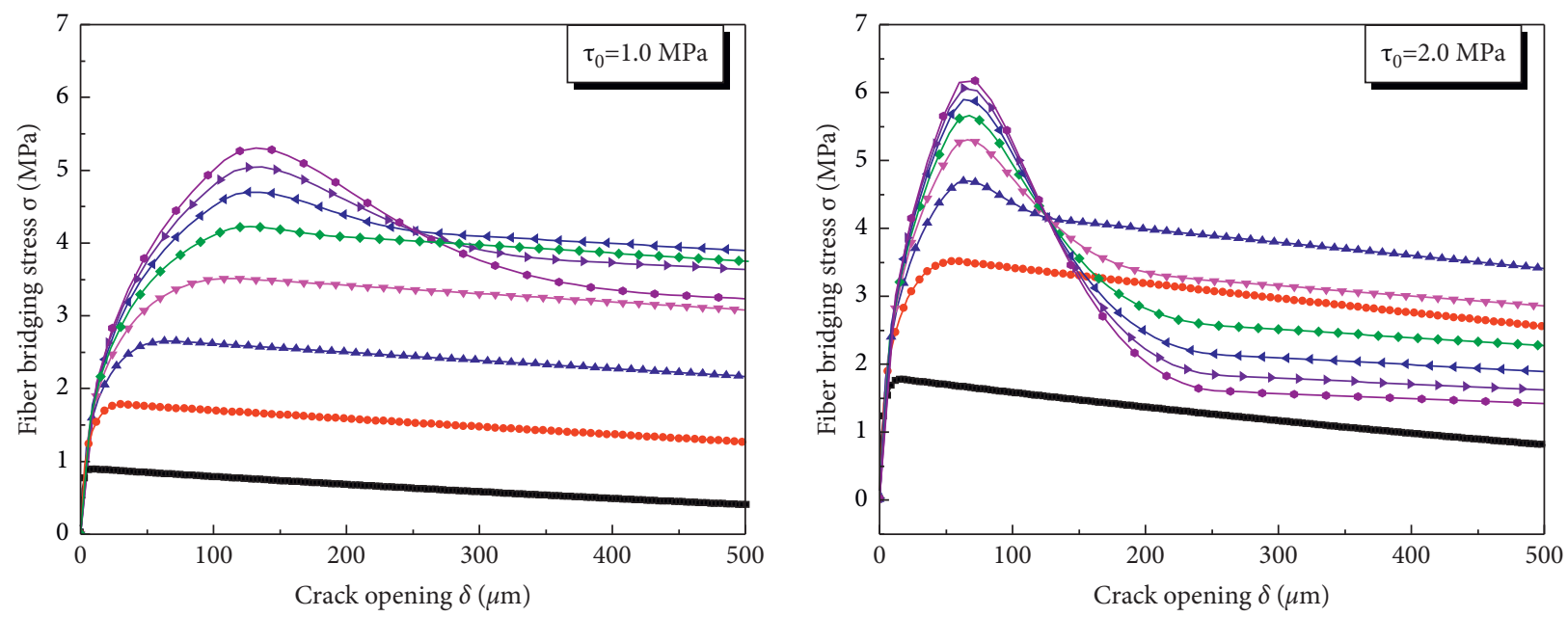
$\longrightarrow \mathrm{L}_{\mathrm{f}}=3 \mathrm{~mm}$
$\longrightarrow \mathrm{L}_{\mathrm{f}}=6 \mathrm{~mm}$
ㄴ $\mathrm{L}_{\mathrm{f}}=9 \mathrm{~mm}$
- $\mathrm{L}_{\mathrm{f}}=12 \mathrm{~mm}$
$\longrightarrow \mathrm{L}_{\mathrm{f}}=15 \mathrm{~mm}$
$\longrightarrow \mathrm{L}_{\mathrm{f}}=18 \mathrm{~mm}$
$\rightarrow \mathrm{L}_{\mathrm{f}}=21 \mathrm{~mm}$
$\rightarrow \mathrm{L}_{\mathrm{f}}=24 \mathrm{~mm}$

(a)

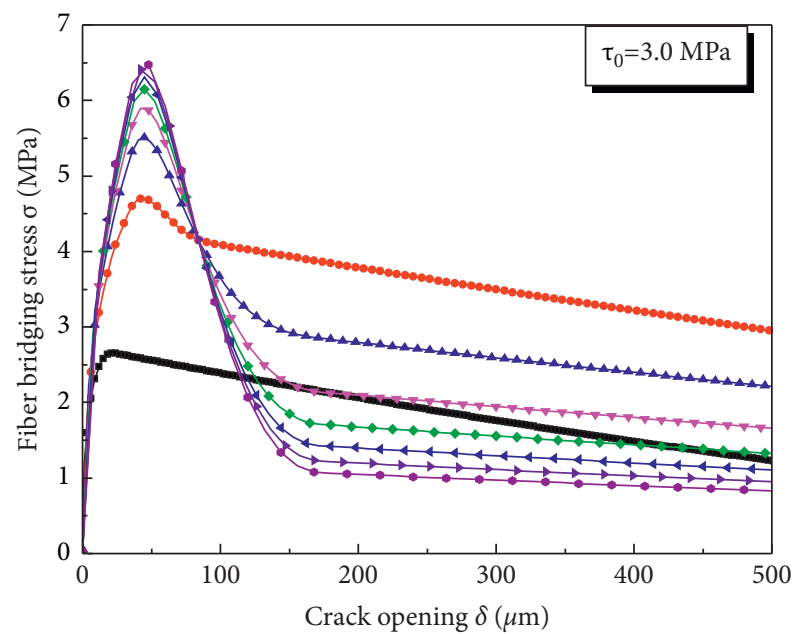
$\longrightarrow \mathrm{L}_{\mathrm{f}}=3 \mathrm{~mm}$
$\longrightarrow \mathrm{L}_{\mathrm{f}}=6 \mathrm{~mm}$
$\because \mathrm{L}_{\mathrm{f}}=9 \mathrm{~mm}$
$\because \mathrm{L}_{\mathrm{f}}=12 \mathrm{~mm}$

$\longrightarrow \mathrm{L}_{\mathrm{f}}=15 \mathrm{~mm}$

— $\mathrm{L}_{\mathrm{f}}=18 \mathrm{~mm}$

$\rightarrow \mathrm{L}_{\mathrm{f}}=21 \mathrm{~mm}$

$\rightarrow \mathrm{L}_{\mathrm{f}}=24 \mathrm{~mm}$

(b)

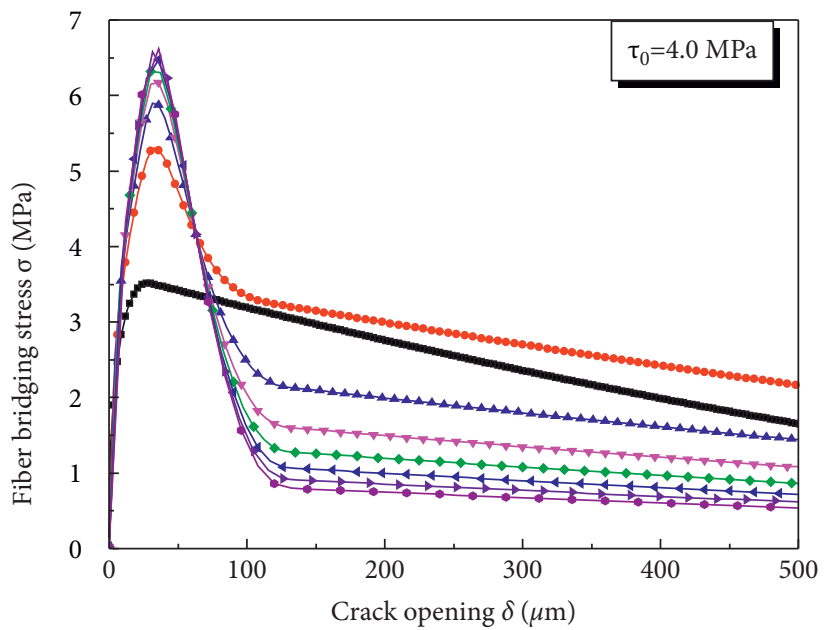

$\because \mathrm{L}_{\mathrm{f}}=15 \mathrm{~mm}$

ㄷ $\mathrm{L}_{\mathrm{f}}=18 \mathrm{~mm}$

$\rightarrow \mathrm{L}_{\mathrm{f}}=21 \mathrm{~mm}$

- $\mathrm{L}_{\mathrm{f}}=24 \mathrm{~mm}$

(d)

FIgURE 6: Continued. 

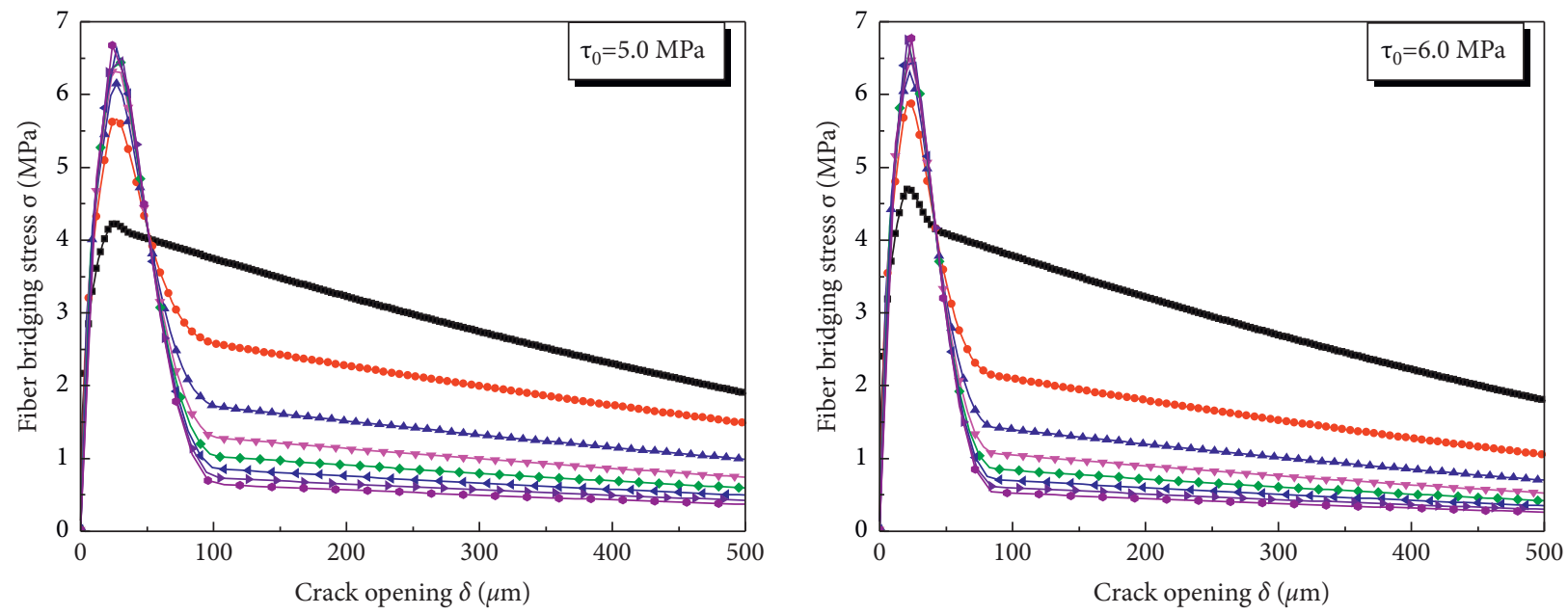
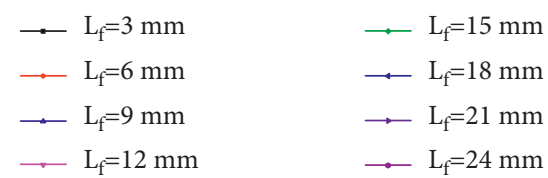

(e)

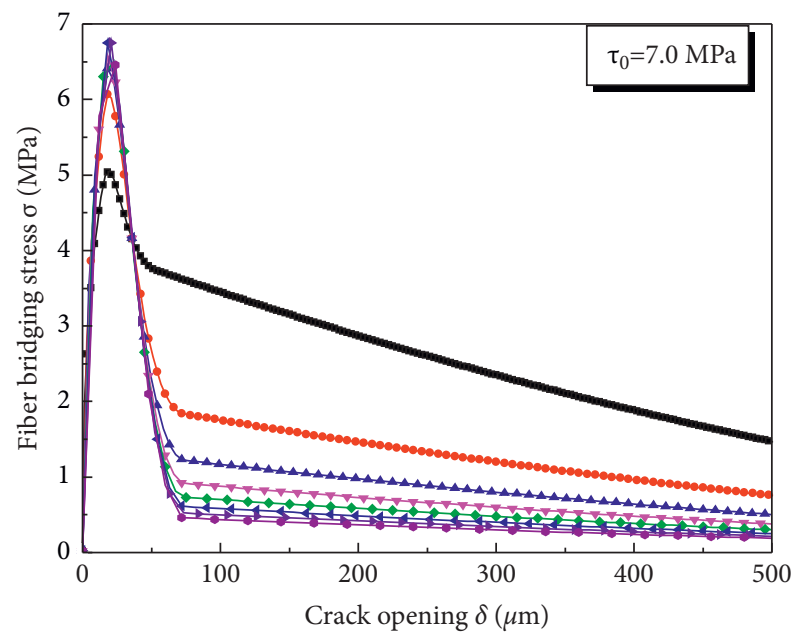

(g)
- $\mathrm{L}_{\mathrm{f}}=3 \mathrm{~mm}$
— $\mathrm{L}_{\mathrm{f}}=6 \mathrm{~mm}$
¿ $\mathrm{L}_{\mathrm{f}}=9 \mathrm{~mm}$
ㄴ $\mathrm{L}_{\mathrm{f}}=12 \mathrm{~mm}$

(f)

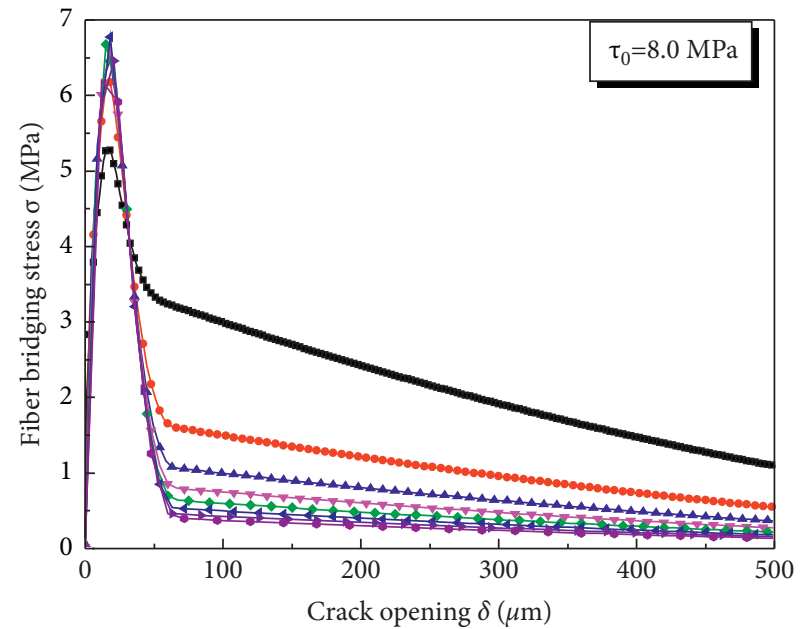

$\longrightarrow \mathrm{L}_{\mathrm{f}}=3 \mathrm{~mm}$
$\longrightarrow \mathrm{L}_{\mathrm{f}}=6 \mathrm{~mm}$
$\longrightarrow \mathrm{L}_{\mathrm{f}}=9 \mathrm{~mm}$
$\longrightarrow \mathrm{L}_{\mathrm{f}}=12 \mathrm{~mm}$

$\because \mathrm{L}_{\mathrm{f}}=15 \mathrm{~mm}$

— $\mathrm{L}_{\mathrm{f}}=18 \mathrm{~mm}$

$\rightarrow \mathrm{L}_{\mathrm{f}}=21 \mathrm{~mm}$

- $\mathrm{L}_{\mathrm{f}}=24 \mathrm{~mm}$

(h)

Figure 6: Curves of the fiber bridging stress versus the crack opening for fiber lengths ranging from $3 \mathrm{~mm}$ to $24 \mathrm{~mm}$ and the fiber/matrix interfacial bonding strength ranging from 1.0 MPa to 8.0 MPa. 


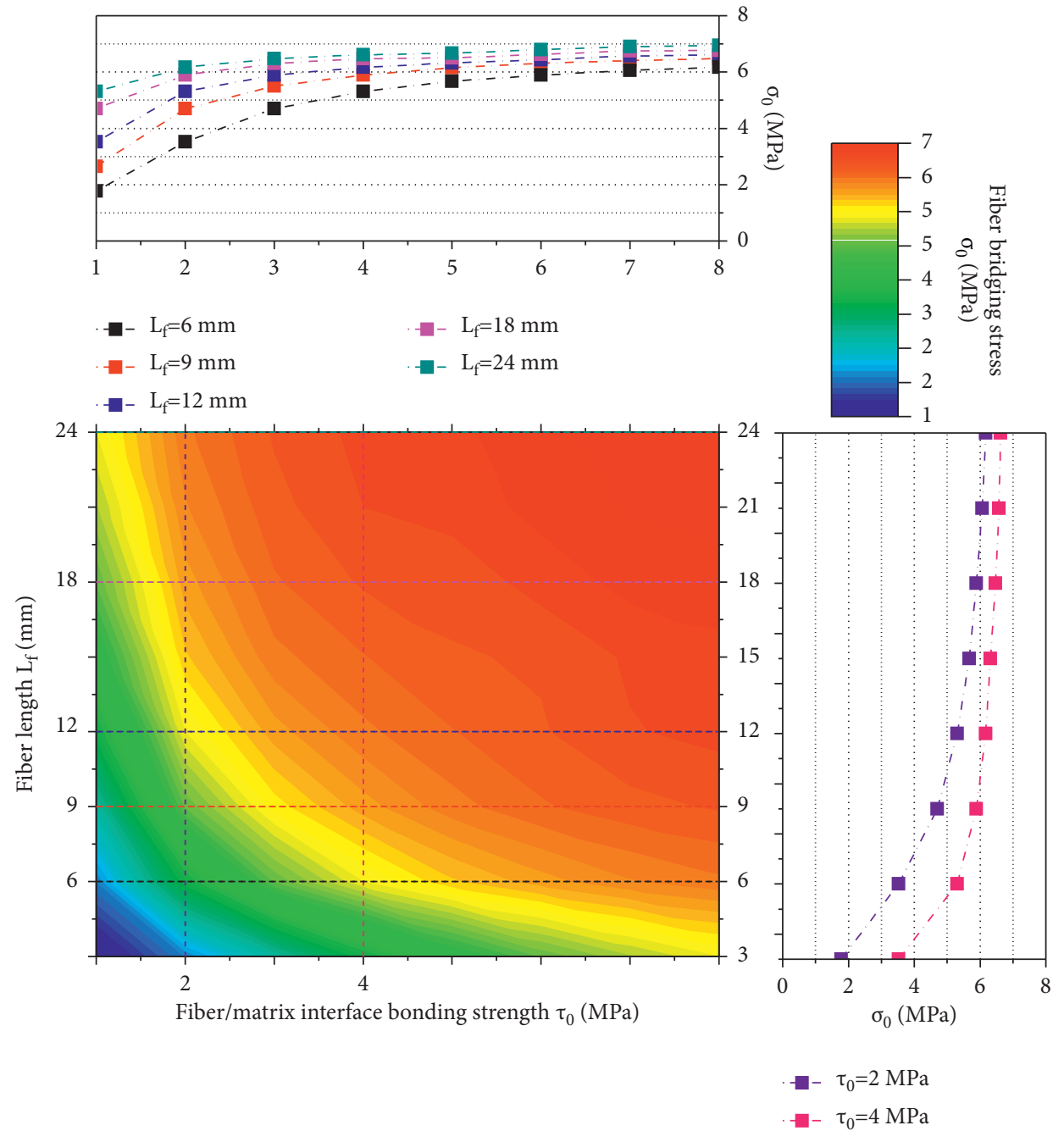

(a)

Figure 7: Continued. 


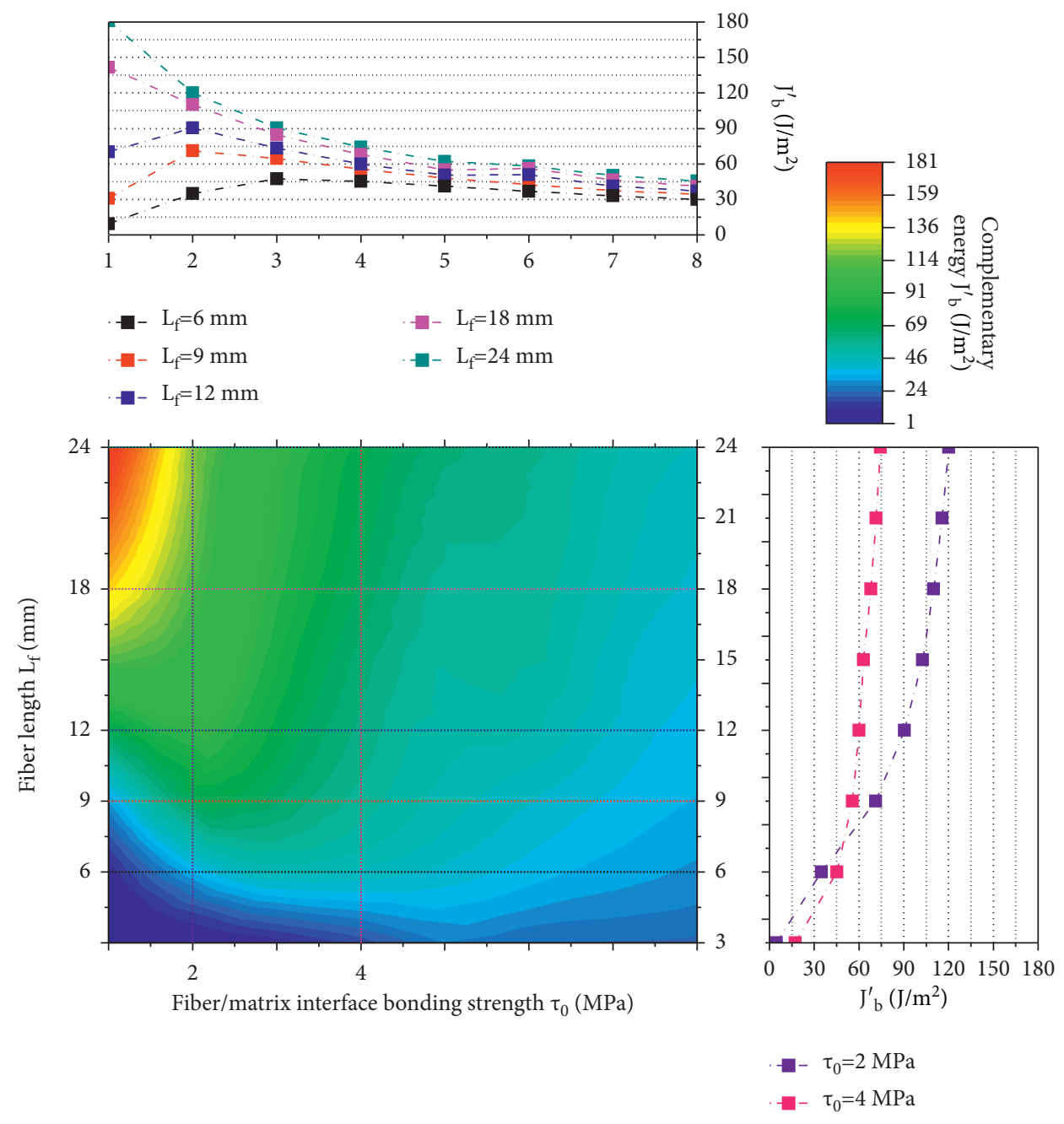

(b)

FIGURE 7: Effect of the fiber length on the bridging stress and complementary energy with various fiber/matrix interfacial bonding strengths. (a) Fiber bridging stress $\sigma_{0}$. (b) Complementary energy $J_{b}^{\prime}$.

pointed out that the theoretical analysis is based on the uniform dispersion of fibers. In practice, overlong fibers will inevitably encounter the problem of difficult dispersion, which will cause a decrease in the effective fiber content and will be explored in subsequent experiments.

\section{Experimental Program}

3.1. Materials and Mixture Preparation. The HDCCs binders were included of Portland cement (P II $42.5 \mathrm{R}$ and P II 52.5 R) and fly ash (Class F), which conformed to Chinese standard GB175-2007 and ASTM C618, respectively. The chemical composition was provided in Table 1. River sand, as fine aggregates, had a maximum size and a fineness modulus of $0.60 \mathrm{~mm}$ and 1.40 , respectively. A polycarboxylate-based high-performance water reducing admixture (HPWR) combined with hydroxypropyl methyl cellulose (HPMC) was utilized to control the fluidity of the paste. In this study, PVA fibers with $6 \mathrm{~mm}, 9 \mathrm{~mm}, 12 \mathrm{~mm}$, $18 \mathrm{~mm}$, and $24 \mathrm{~mm}$ were adopted to study the influence of the fiber length on the workability and mechanical properties of HDCCs, and the aspect ratio of PVA fiber ranges from 154 to 615 . The physical/mechanical properties and geometry of the PVA fibers were provided in Table 2, and Figure 8 shows visual images of PVA fibers of various lengths.

To achieve a compressive strength that ranges from $30 \mathrm{MPa}$ to $80 \mathrm{MPa}$ for the HDCCs, fly ash/cement ratios of 0.80 and 0.60 and water/binder ratios of $0.30,0.25$, and 0.22 were selected. The mixture proportions of HDCCs are listed in Table 3. For the preparation of HDCCs, the mixture proportion of the matrix is fixed, and only the fiber length is variable. A typical fiber volume fraction of $2 \%$ (by total volume) was used. Specifically, P II $52.5 \mathrm{R}$ cement was only used to obtain high-strength HDCCs for the mixture of $0.22-60 \%$, whereas the other mixtures used P II $42.5 \mathrm{R}$ cement. All the HDCCs mixtures were prepared using a mortar mixer with a capacity of $20 \mathrm{~L}$. The preparation steps were as follows. First, the binders and river sand were dry mixed for $2 \mathrm{~min}$; subsequently, the water were gradually 
TABLe 1: Chemical composition of cement and fly ash (mass fraction\%).

\begin{tabular}{|c|c|c|c|c|c|c|c|c|c|}
\hline Binding material & $\mathrm{CaO}$ & $\mathrm{SiO}_{2}$ & $\mathrm{Al}_{2} \mathrm{O}_{3}$ & $\mathrm{Fe}_{2} \mathrm{O}_{3}$ & $\mathrm{MgO}$ & $\mathrm{SO}_{3}$ & $\mathrm{~K}_{2} \mathrm{O}$ & $\mathrm{Na}_{2} \mathrm{O}$ & Loss \\
\hline P.II $42.5 \mathrm{R}$ cement & 60.60 & 21.84 & 6.49 & 3.70 & 1.77 & 2.24 & 0.32 & 0.51 & 2.53 \\
\hline P.II 52.5 cement & 63.05 & 20.58 & 5.16 & 3.39 & 1.57 & 2.57 & 0.27 & 0.31 & 3.10 \\
\hline Fly ash & 6.06 & 49.96 & 33.02 & 4.52 & 1.17 & 0.62 & 0.98 & 0.66 & 3.01 \\
\hline
\end{tabular}

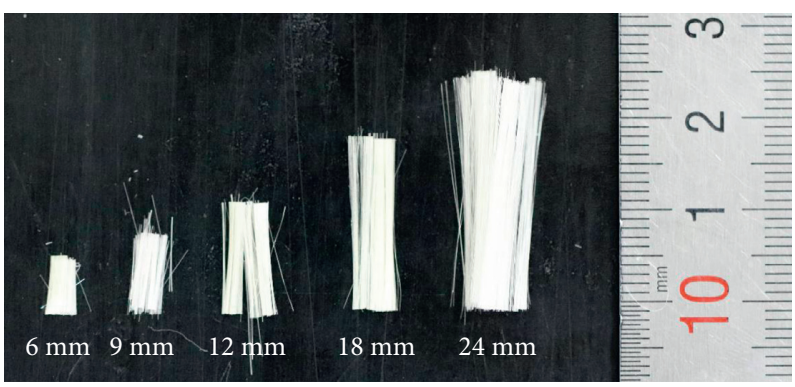

Figure 8: Visual images of PVA fibers of various lengths.

TABle 2: Physical/mechanical properties and geometry of PVA fibers.

\begin{tabular}{lcccccc}
\hline $\begin{array}{l}\text { Fiber } \\
\text { type }\end{array}$ & $\begin{array}{c}\text { Tensile strength } \sigma_{f u} \\
(\mathrm{MPa})\end{array}$ & $\begin{array}{c}\text { Elastic modulus } E_{f} \\
(\mathrm{GPa})\end{array}$ & $\begin{array}{c}\text { Diameter } d_{f} \\
(\mu \mathrm{m})\end{array}$ & $\begin{array}{c}\text { Elongation } \varepsilon_{f} \\
(\%)\end{array}$ & $\begin{array}{c}\text { Length } L_{f} \\
(\mathrm{~mm})\end{array}$ & $\begin{array}{c}\text { Aspect ratio } \\
\text { PVA }\end{array}$ \\
$\begin{array}{l}\text { Piber } \\
\text { fiber }\end{array}$ & 1260 & 30 & 39 & $5-7$ & $6,9,12$, & $154,231,308,462$, \\
18,24 & 615 \\
\hline
\end{tabular}

TABLE 3: Mixture proportions of HDCCs by weight.

\begin{tabular}{lccccccc}
\hline Mixture & Cement & Fly ash & Sand & Water & HPWR/binder (\%) & HPMC/Binder (\%) & PVA fiber (by volume) \\
\hline $0(\%) .30-80 \%-\mathrm{x}$ & 0.2 & 0.8 & 0.3 & 0.3 & 0.17 & 0.04 & 0.04 \\
$0.30-60 \%-\mathrm{x}$ & 0.4 & 0.6 & 0.3 & 0.3 & 0.19 & 0.05 & 2.0 \\
$0.25-60 \%-\mathrm{x}$ & 0.4 & 0.6 & 0.3 & 0.25 & 0.32 & 0.1 & 2.0 \\
$0.22-60 \%-\mathrm{x}$ & 0.4 & 0.6 & 0.3 & 0.22 & 1.0 & 2.0 \\
\hline
\end{tabular}

Note. The symbol ' $\mathrm{x}$ ' represents the fiber length, that is, $0.30-80 \%-6$ is a mixture with a water/binder ratio of 0.30 , a fly ash/cement ratio of $80 \%$, and PVA fibers with a length of $6 \mathrm{~mm}$.

added to the dry mixture and mixed for another 5-10 min, and HPWR and HPMC were added to adjust the paste fluidity; finally, the PVA fibers were added and then mixed for another $5 \mathrm{~min}$. The fresh HDCCs were cast into moulds and covered with plastic sheets to prevent moisture loss. The specimens were demoulded after $24 \mathrm{~h}$ and then cured at a temperature of $20 \pm 1^{\circ} \mathrm{C}$ and relative humidity of $95 \%$ for $28 \mathrm{~d}$.

The workability of fresh HDCC was measured using a Hägermann flow table (cone dimensions: $70 \mathrm{~mm}$ top diameter, $100 \mathrm{~mm}$ base diameter, and $60 \mathrm{~mm}$ height) conforming to the requirements in ASTM C1437. The fresh HDCCs exhibited distinct fluidity states with the incorporation of PVA fibers of different lengths. This is because longer fibers can anchor more cement paste, especially hydrophilic PVA fibers [41]. The anchoring effect restricts the flow of HDCCs paste and leads to worse composite fluidity, as illustrated in Figure 9. In addition, Figure 10(b) shows that fibers with lengths of $18 \mathrm{~mm}$ and $24 \mathrm{~mm}$ tended to twine on the mixer blade during the mixing procedure, even though this phenomenon was almost eliminated, which

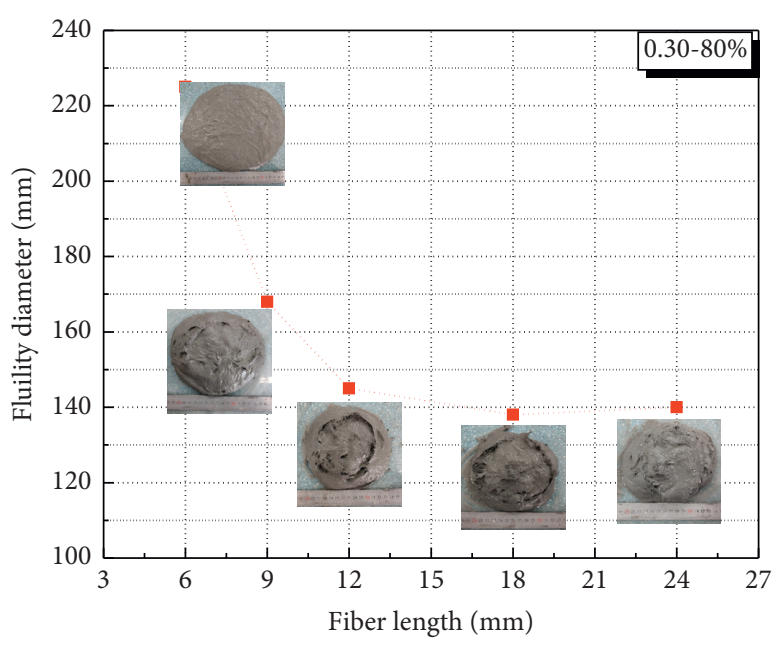

FIGURE 9: Fluidity diameters of $0.30-80 \%$-x mixture.

resulted in a decrease in the effective content of fibers. Consequently, the fiber bridging capacities will be greatly affected, which will be discussed in subsequent sections. For 


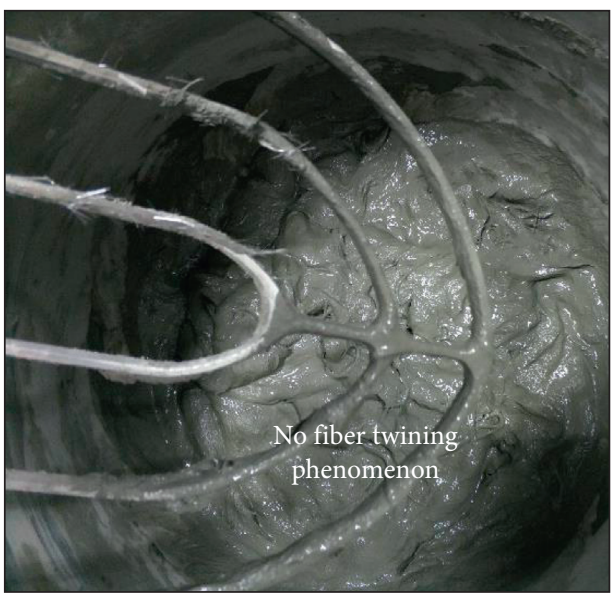

(a)

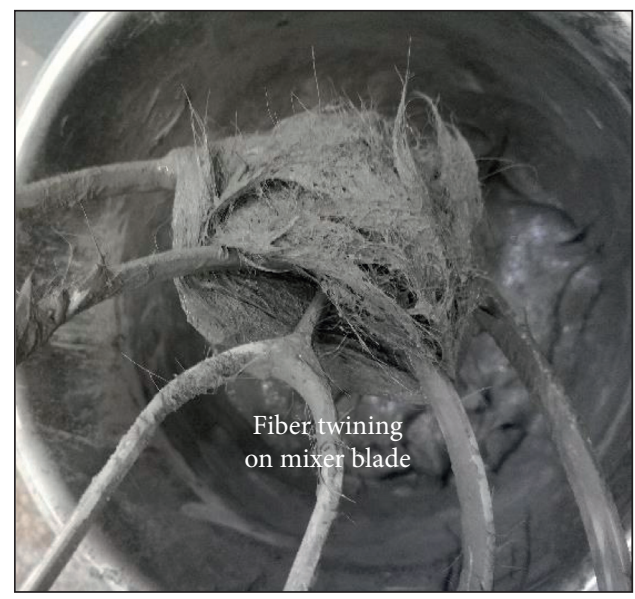

(b)

Figure 10: Mixing state of (a) $0.30-80 \%-9$ and (b) $0.30-80 \%-18$.

fibers with lengths of $6 \mathrm{~mm}, 9 \mathrm{~mm}$, and $12 \mathrm{~mm}$, twining barely occurred, as shown in Figure 10(a).

3.2. Test Programs. The compressive test was conducted in accordance with standard EN 1015-11. Six cubes of $40 \mathrm{~mm} \times 40 \mathrm{~mm} \times 40 \mathrm{~mm}$ were tested for each mixture, and the loading rate was controlled as $50 \mathrm{~N} / \mathrm{s}$.

Four-point bending test were conducted in accordance with standard test method for flexural performance of fiberreinforced concrete (ASTM C1609). Three plate specimen of $300 \mathrm{~mm} \times 75 \mathrm{~mm} \times 25 \mathrm{~mm}$ were tested for each mixture, a loading span was set as a length of $240 \mathrm{~mm}$, and the midspan deflection was measured by a Linear Variable Differential Transformer (LVDT) placed at the center of each specimen. The loading was applied at a displacement rate of $0.5 \mathrm{~mm} / \mathrm{min}$. The device for four-point bending test was shown in Figure 11.

Uniaxial tension test was performed in accordance with the JSCE recommendation for design and construction of high-performance fiber-reinforced cement composites (HPFRCC). Three dogbone-shaped specimens with a cross section of $13 \mathrm{~mm} \times 30 \mathrm{~mm}$ were tested for each mixture. The tensile strain was measured by an external LVDT attached diametrically to the specimens. Figure 12 showed the specimen geometry and test setup. The uniaxial tension test was conducted under quasistatic loading conditions at a displacement rate of $0.2 \mathrm{~mm} / \mathrm{s}$.

\section{Results and Discussions}

4.1. Compressive Properties. The compressive strength of the matrix and the HDCCs with different fiber lengths are shown in Figure 13(a), and the increase/decrease in the compressive strength with respect to the matrix is shown in Figure 13(b).

As shown in Figure 13(a), the compressive strength of the HDCCs matrices reached $31.5 \mathrm{MPa}, 47.5 \mathrm{MPa}, 61.5 \mathrm{MPa}$, and $81.0 \mathrm{MPa}$ for the $0.30-80 \%, 0.30-60 \%, 0.25-60 \%$, and $0.22-60 \%$ mixtures, respectively. For the addition of PVA

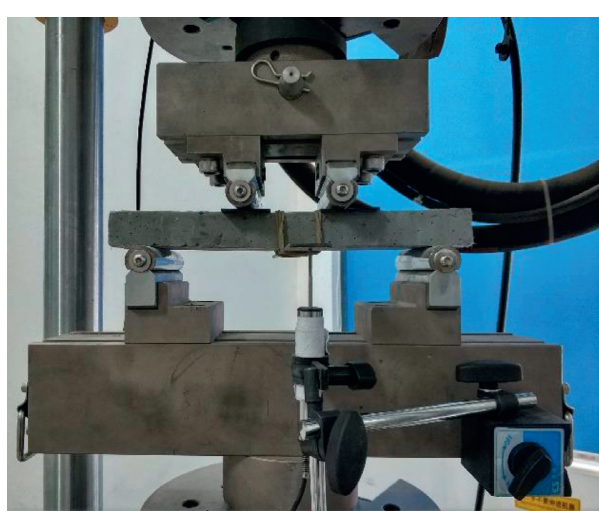

Figure 11: Four-point bending test setup.

fiber, the compressive strength of the $0.30-80 \%, 0.30-60 \%$, and $0.25-60 \%$ series were enhanced regardless of the fiber length. However, a decreasing tendency was exhibited for the $0.22-60 \%$ series. In general, the addition of fibers can result in two opposite (positive and negative) effects on the compressive properties [41-43]. On the one hand, the randomly distributed fibers can produce a strong lateral binding force and constrain lateral expansion of HDCCs, which restricts the rapid expansion of cracks and improves the composite compressive properties. Such behaviour can be likened to the lateral binding force generated by stirrups in the confined concrete. The distinguishing feature is that the binding force generated by the fibers is an internal binding force, that generated by the stirrups is an external binding force, and the schematic on two kinds of binding force is shown in Figure 14 [42]. On the other hand, the addition of fibers in cementitious composites can be regarded as flaws, and some artificial pores can be more easily introduced due to the worse workability, which introduces a negative effect on the compressive properties $[42,44]$. Consequently, the compressive strength of HDCCs was dependent on the combined actions of these opposite aspects. For the $0.30-80 \%, 0.30-60 \%$, and $0.25-60 \%$ series, the positive effect was dominant compared with the negative 


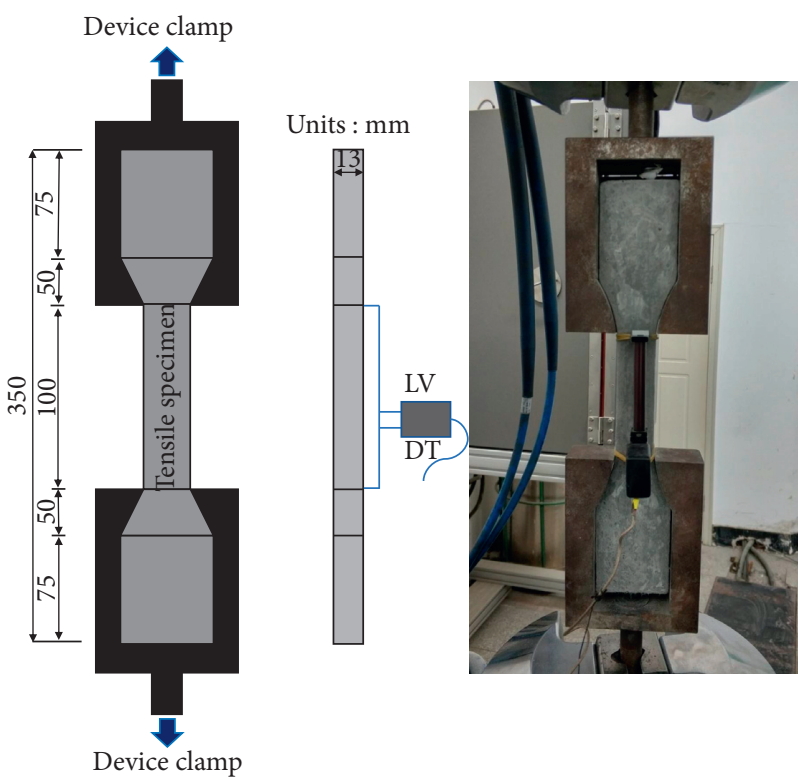

Figure 12: Uniaxial tension specimen and test setup.

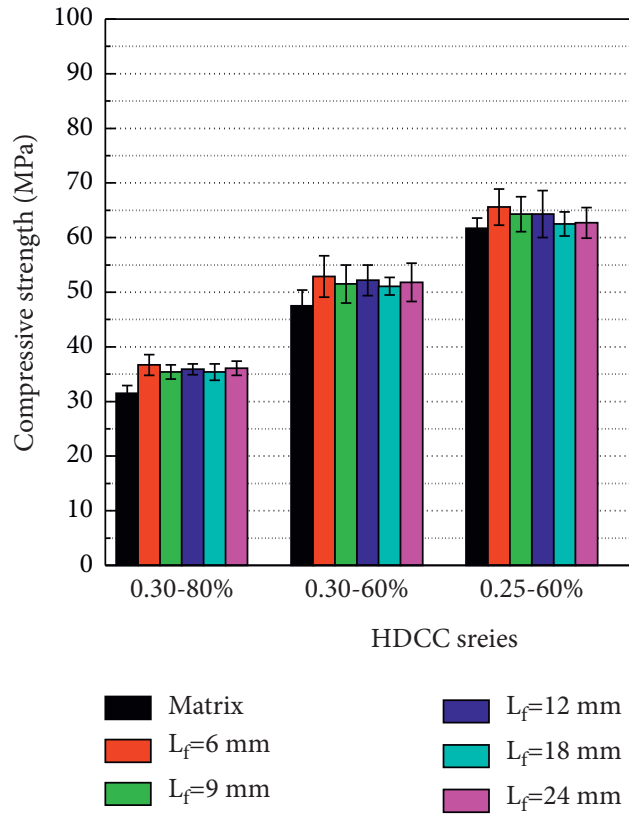

(a)

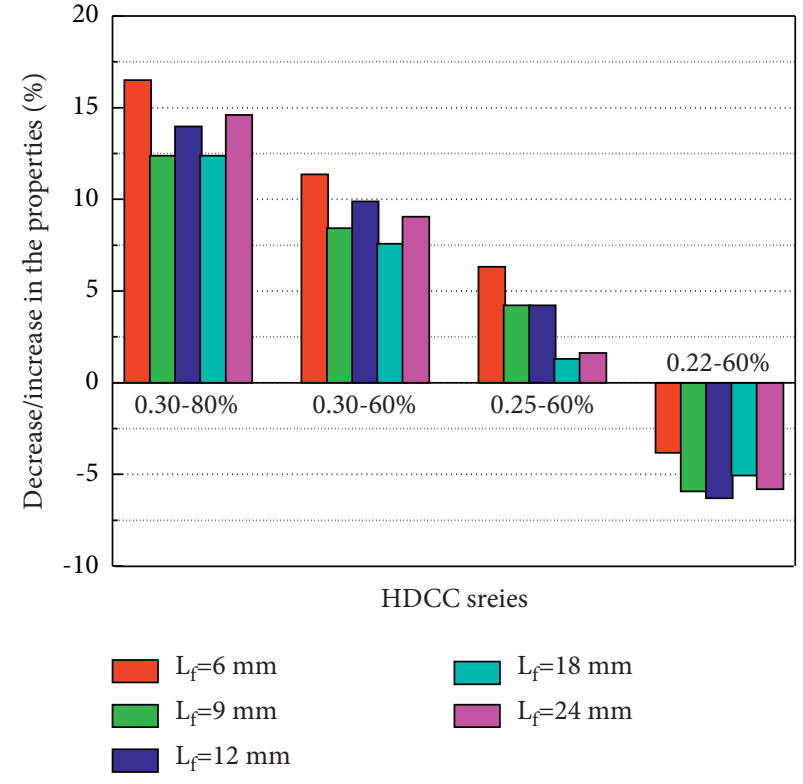

(b)

Figure 13: Compressive strengths of the matrix and HDCCs with different PVA fiber lengths. (a) Compressive strengths. (b) Decreased/increased respect to the matrix.

effect, and the compressive strength increased due to the incorporation of PVA fibers. Conversely, the negative effect was dominant for the $0.22-60 \%$ series because the lower water/binder ratio caused the matrix to be quite compact, and high sensitivity to flaws and artificial pores was exhibited.

The literature also demonstrated that shorter fibers increase the compressive strength further compared with that of longer fibers due to better dispersion and consolidation effect, although long fibers can produce stronger bridging stress [41]. As shown in Figure 13(a), the HDCCs with $6 \mathrm{~mm}$ fibers achieved slightly higher compressive strength. Nevertheless, Figure 13(b) indicates that the most striking differences in compressive strength were less than $5.0 \%$. The compressive properties were slightly affected by the fiber length, which mainly depended on the matrix properties. When PVA fibers with lengths from $6 \mathrm{~mm}$ to $24 \mathrm{~mm}$ and a volume content of $2 \%$ were added, the compressive strengths of the HDCCs were almost the same, although there was a slight difference. 


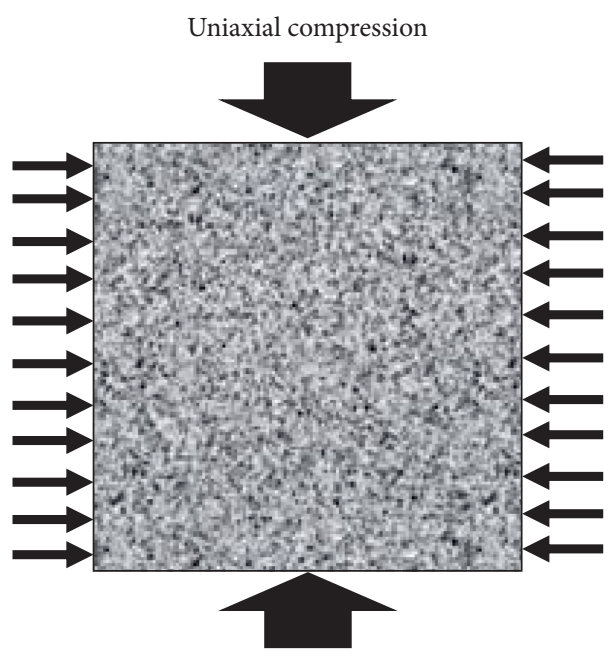

(a)

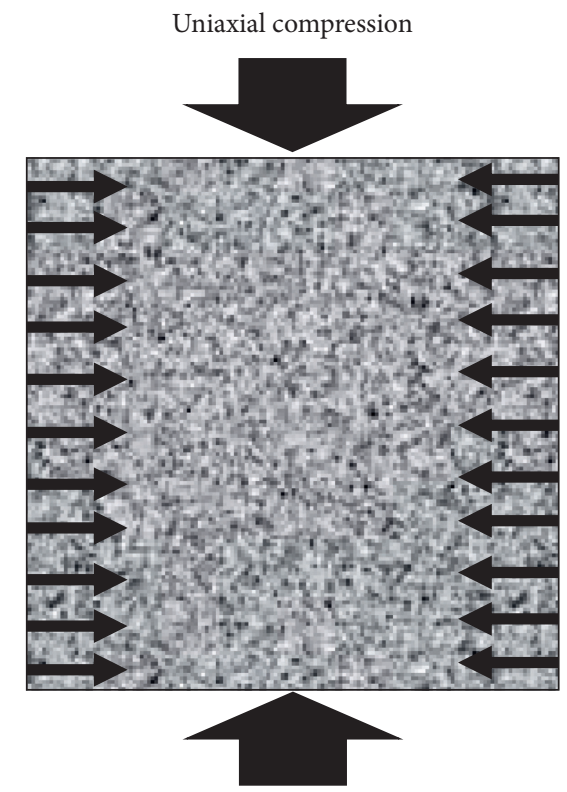

(b)

Figure 14: The schematic on the lateral binding force [42]. (a) External lateral binding force produced by stirrups. (b) Internal lateral binding force produced by fibers.

As mentioned, the ranges of the compressive strength in this study were representative of the PVA-HDCCs. Based on the limitation of the mechanical properties of PVA fibers, most fibers are prone to rupture if a higher-strength matrix (larger than $80 \mathrm{MPa}$ ) is employed [40]; hence, the fiber bridging capacity will be insufficient to maintain steady-state propagation of cracks. Therefore, the exploration of the effect of the fiber length on the mechanical performance is justified and worthy in this study.

4.2. Four-Point Bending Properties. Figure 15 shows the flexural stress versus midspan deflection curves obtained from the four-point bending tests, and the flexural properties are summarized in Table 4. As shown in Figure 15, all the HDCCs specimens were characterized by deflectionhardening behaviour and multiple cracks. For identical mixtures with different fiber lengths, the flexural stress/ deformation capacities of the specimens were different due to the diverse bridging capacities, and the cracking patterns in the pure bending region are illustrated in Figure 16(a). For the different mixtures with identical fiber lengths, more significant differences in flexural properties can also be found, and the cracking pattern in the pure bending region is illustrated in Figure 16(b).

The stress-deflection curves in the initial cracking stage are shown in Figure 17(a), and the initial cracking strength is shown in Figure 17(b). Significant deflection-hardening behaviour after the initial cracking point can be clearly observed (Figure 17(a)). The fibers across the crack plane hold the applied load and allow the increase in the flexural stress to be maintained. With the expansion of cracks, the sufficient bridging stress was beyond the initial cracking strength. In general, the initial cracking strength was significantly affected by the matrix properties [45]. Figure 17(b) shows that the HDCCs with different fiber lengths have similar initial cracking strengths, although there are fluctuations. HDCCs with a higher strength (0.22-80\%) displayed a higher initial cracking strength $(8.82 \mathrm{MPa})$, which were $128.8 \% \quad(6.85 \mathrm{MPa}), \quad 154.7 \%$ $(5.70 \mathrm{MPa})$, and $191.7 \%(4.60 \mathrm{MPa})$ of the $0.30-60 \%$, $0.30-60 \%$, and $0.25-60 \%$ series, respectively.

The effect of the fiber bridging capacity on the flexural properties is mainly reflected in the postcracking stage. The bridging stress is transferred to the surrounding matrix by the fiber/matrix interface, and then cracks are formed again when the transferred stress exceeds the cracking strength. The above process continues accompanied by multiple cracks in the pure bending region [46]. Finally, the bridging effect cannot sustain the tensile stresses caused by the external moment, and the flexural stress decreases gradually with unstable opening of the dominant crack. Accordingly, a stronger bridging capacity can result in a higher ultimate flexural strength and larger deflection. The effects of the fiber length on the ultimate flexural strength, midspan deflection, and fiber bridging energy dissipation are presented in Figure 18. The area of the curves for the flexural stress versus the midspan deflection from the initial cracking point $\sigma_{i}\left(y_{i}\right)$ to the ultimate cracking point $\sigma_{u}\left(y_{u}\right)$ provides the fiber bridging energy dissipation $G_{B}$ under four-point bending.

According to Figure 18, the HDCCs with $9 \mathrm{~mm}$ fibers or $12 \mathrm{~mm}$ fibers generally achieve a higher ultimate flexural strength and larger midspan deflection regardless of the matrix strength, and shorter or longer fibers cause the HDCCs to exhibit slightly weaker flexural properties. According to the theoretical analysis above, shorter fibers provide a weaker bridging capacity; thus, the results are 


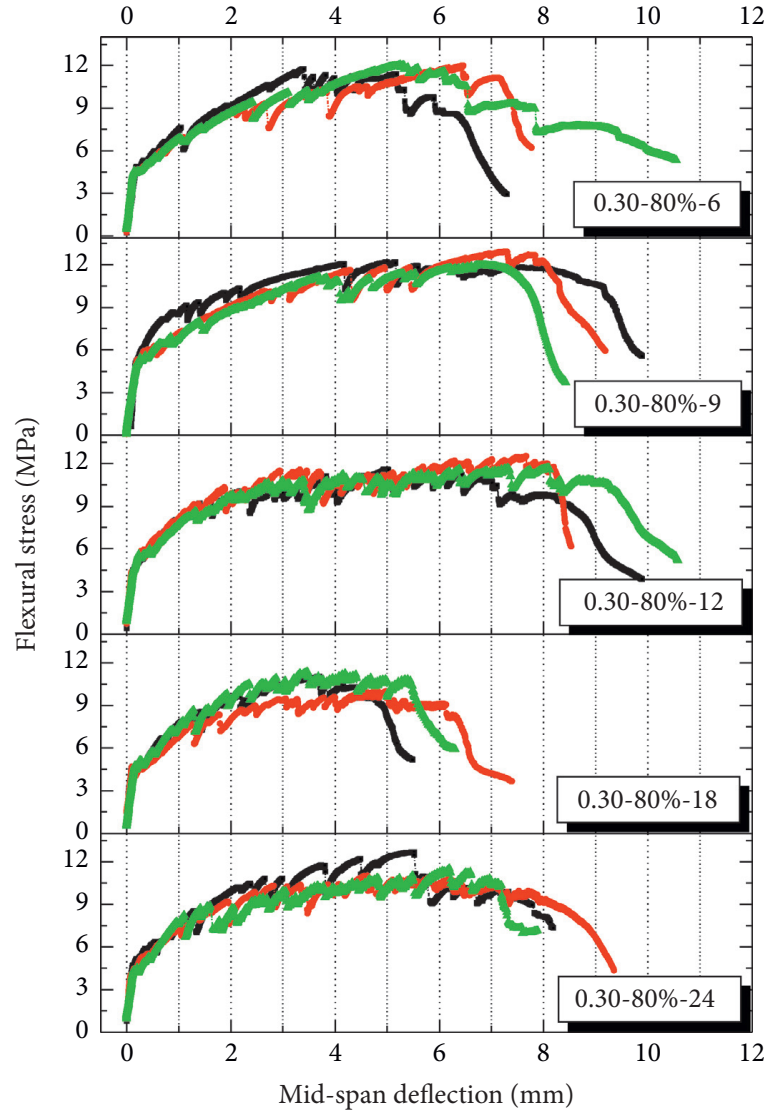

(a)

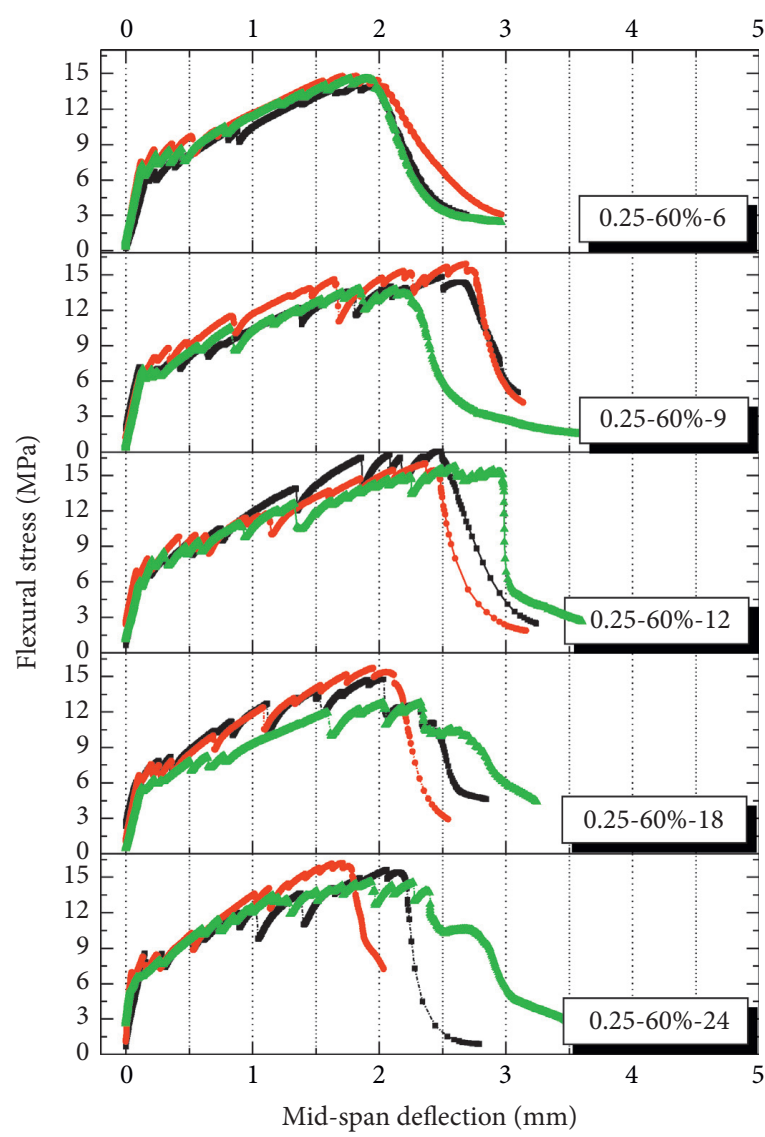

(c)

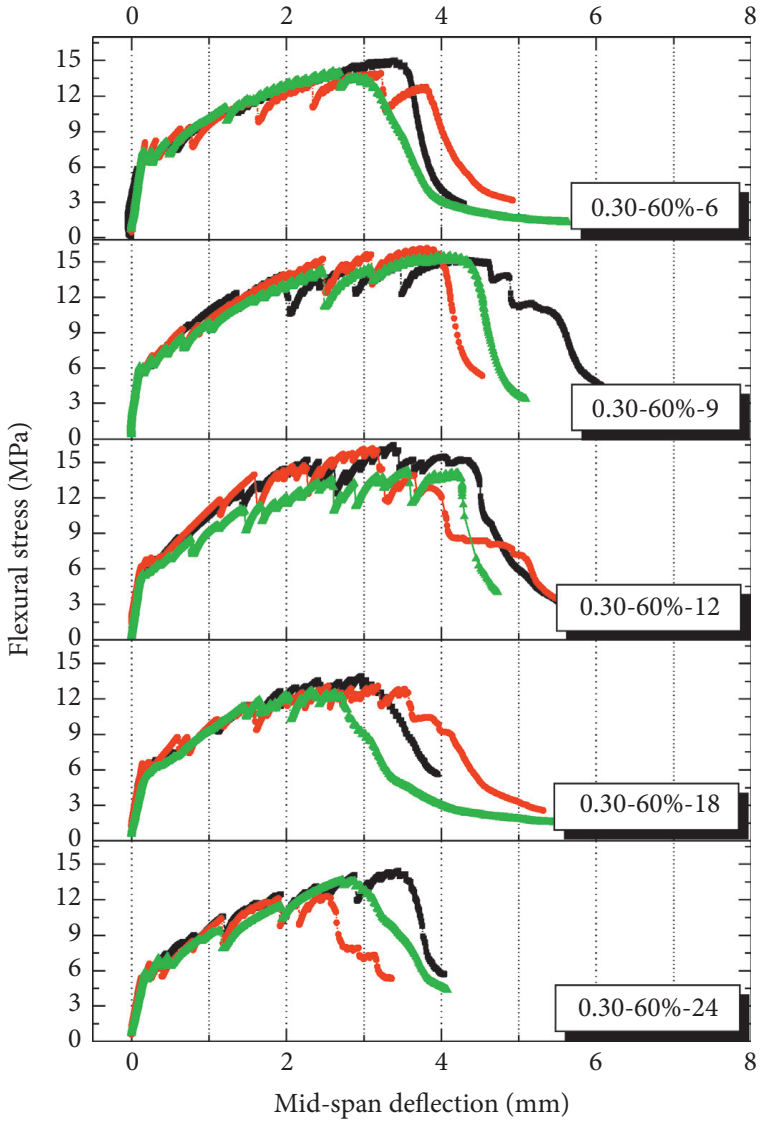

(b)

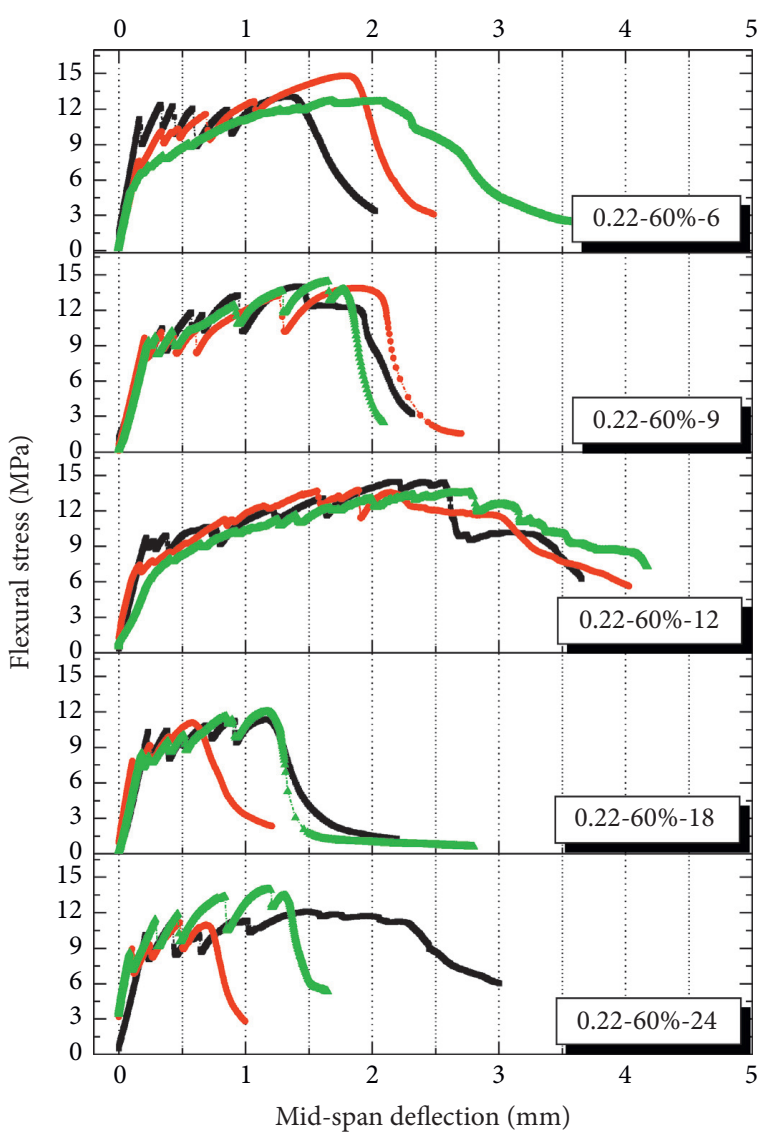

(d)

FIGURE 15: Four-point flexural stress versus midspan deflection curves. (a) $0.30-80 \%$ series. (b) $0.30-60 \%$ series. (c) $0.25-60 \%$ series. (d) 
TABLE 4: Mechanical properties of the HDCCs with different fiber lengths.

\begin{tabular}{|c|c|c|c|c|c|c|c|c|}
\hline \multirow{2}{*}{ HDCCs series } & \multirow{2}{*}{$L_{f}(\mathrm{~mm})$} & \multirow{2}{*}{$\sigma_{c s}(\mathrm{MPa})$} & \multicolumn{4}{|c|}{ Four-point bending properties } & \multicolumn{2}{|c|}{ Tensile properties } \\
\hline & & & $\sigma_{i f}(\mathrm{MPa})$ & $\sigma_{u f}(\mathrm{MPa})$ & $\delta_{u f}(\mathrm{~mm})$ & $G_{B}(\mathrm{MPa})$ & $\sigma_{t s}(\mathrm{MPa})$ & $\varepsilon_{t s}(\%)$ \\
\hline \multirow{5}{*}{$0.30-80 \%$} & 6 & $36.7 \pm 1.9$ & $4.47 \pm 0.32$ & $11.9 \pm 0.2$ & $5.03 \pm 0.16$ & $43.50 \pm 16$ & - & - \\
\hline & 9 & $35.4 \pm 1.3$ & $5.15 \pm 0.15$ & $12.3 \pm 0.5$ & $6.84 \pm 0.5$ & $67.0 \pm 5$ & $4.91 \pm 0.51$ & $2.52 \pm 0.31$ \\
\hline & 12 & $35.9 \pm 1.0$ & $4.48 \pm 0.15$ & $11.8 \pm 0.8$ & $8.43 \pm 1.1$ & $76.17 \pm 12$ & $4.92 \pm 0.41$ & $2.34 \pm 0.43$ \\
\hline & 18 & $35.4 \pm 1.5$ & $4.71 \pm 0.15$ & $10.9 \pm 0.3$ & $4.71 \pm 1.0$ & $40.14 \pm 10$ & - & - \\
\hline & 24 & $36.1 \pm 1.3$ & $4.35 \pm 0.35$ & $11.7 \pm 1.0$ & $5.79 \pm 0.4$ & $52.60 \pm 2$ & - & - \\
\hline \multirow{5}{*}{$0.30-60 \%$} & 6 & $52.9 \pm 3.8$ & $5.82 \pm 0.9$ & $14.3 \pm 0.7$ & $3.1 \pm 0.4$ & $33.08 \pm 5$ & - & - \\
\hline & 9 & $51.5 \pm 3.5$ & $5.86 \pm 0.43$ & $15.4 \pm 0.5$ & $4.23 \pm 0.4$ & $50.50 \pm 5$ & $4.69 \pm 0.28$ & $2.05 \pm 0.17$ \\
\hline & 12 & $52.2 \pm 2.8$ & $5.72 \pm 0.49$ & $14.6 \pm 1.8$ & $3.57 \pm 0.6$ & $40.43 \pm 6$ & $4.91 \pm 0.27$ & $1.74 \pm 0.43$ \\
\hline & 18 & $51.1 \pm 1.6$ & $5.64 \pm 0.9$ & $13.1 \pm 0.8$ & $2.94 \pm 0.6$ & $30.12 \pm 6$ & - & - \\
\hline & 24 & $51.8 \pm 3.5$ & $5.45 \pm 0.44$ & $13.4 \pm 1.0$ & $2.90 \pm 0.6$ & $28.09 \pm 5$ & - & - \\
\hline \multirow{5}{*}{$0.25-60 \%$} & 6 & $66.6 \pm 3.3$ & $7.16 \pm 0.4$ & $14.4 \pm 0.3$ & $1.89 \pm 0.1$ & $19.39 \pm 1.8$ & - & - \\
\hline & 9 & $64.3 \pm 3.2$ & $7.00 \pm 0.16$ & $15.3 \pm 1.1$ & $2.47 \pm 0.3$ & $27.04 \pm 4.5$ & $4.74 \pm 0.15$ & $1.67 \pm 0.25$ \\
\hline & 12 & $64.3 \pm 4.3$ & $6.93 \pm 0.73$ & $15.8 \pm 0.2$ & $2.47 \pm 0.2$ & $28.46 \pm 1.5$ & $5.87 \pm 0.31$ & $1.05 \pm 0.25$ \\
\hline & 18 & $62.5 \pm 2.2$ & $6.50 \pm 0.48$ & $15.2 \pm 0.5$ & $2.10 \pm 0.2$ & $21.36 \pm 0.7$ & - & - \\
\hline & 24 & $62.7 \pm 2.8$ & $6.68 \pm 0.35$ & $15.2 \pm 0.8$ & $2.00 \pm 0.3$ & $23.09 \pm 2.2$ & - & - \\
\hline \multirow{5}{*}{$0.22-60 \%$} & 6 & $77.9 \pm 5.1$ & $8.37 \pm 0.15$ & $13.4 \pm 1.0$ & $1.75 \pm 0.4$ & $18.08 \pm 4$ & - & - \\
\hline & 9 & $76.2 \pm 4.2$ & $9.39 \pm 0.5$ & $14 \pm 0.4$ & $1.66 \pm 0.2$ & $16.73 \pm 2.3$ & $6.08 \pm 0.4$ & $0.40 \pm 0.03$ \\
\hline & 12 & $75.9 \pm 3.7$ & $8.60 \pm 1.5$ & $13.8 \pm 0.6$ & $2.50 \pm 0.3$ & $26.58 \pm 3.7$ & $5.67 \pm 0.11$ & $0.39 \pm 0.08$ \\
\hline & 18 & $76.9 \pm 5.0$ & $8.80 \pm 1.4$ & $11.5 \pm 0.4$ & $0.98 \pm 0.4$ & $7.98 \pm 3.6$ & - & - \\
\hline & 24 & $76.3 \pm 4.5$ & $8.92 \pm 0.7$ & $12.8 \pm 0.9$ & $1.13 \pm 0.4$ & $10.67 \pm 4.2$ & - & - \\
\hline
\end{tabular}

$\sigma_{c s}$ is the compressive strength, $\sigma_{i f}$ is the initial cracking flexural strength, $\sigma_{u f}$ is the ultimate flexural strength, and $\delta_{u f}$ is the ultimate midspan deflection. $G_{B}$ is the fiber bridging energy dissipation under four-point bending. $\sigma_{t s}$ is the ultimate tensile strength, and $\varepsilon_{t s}$ is the ultimate tensile ductility.
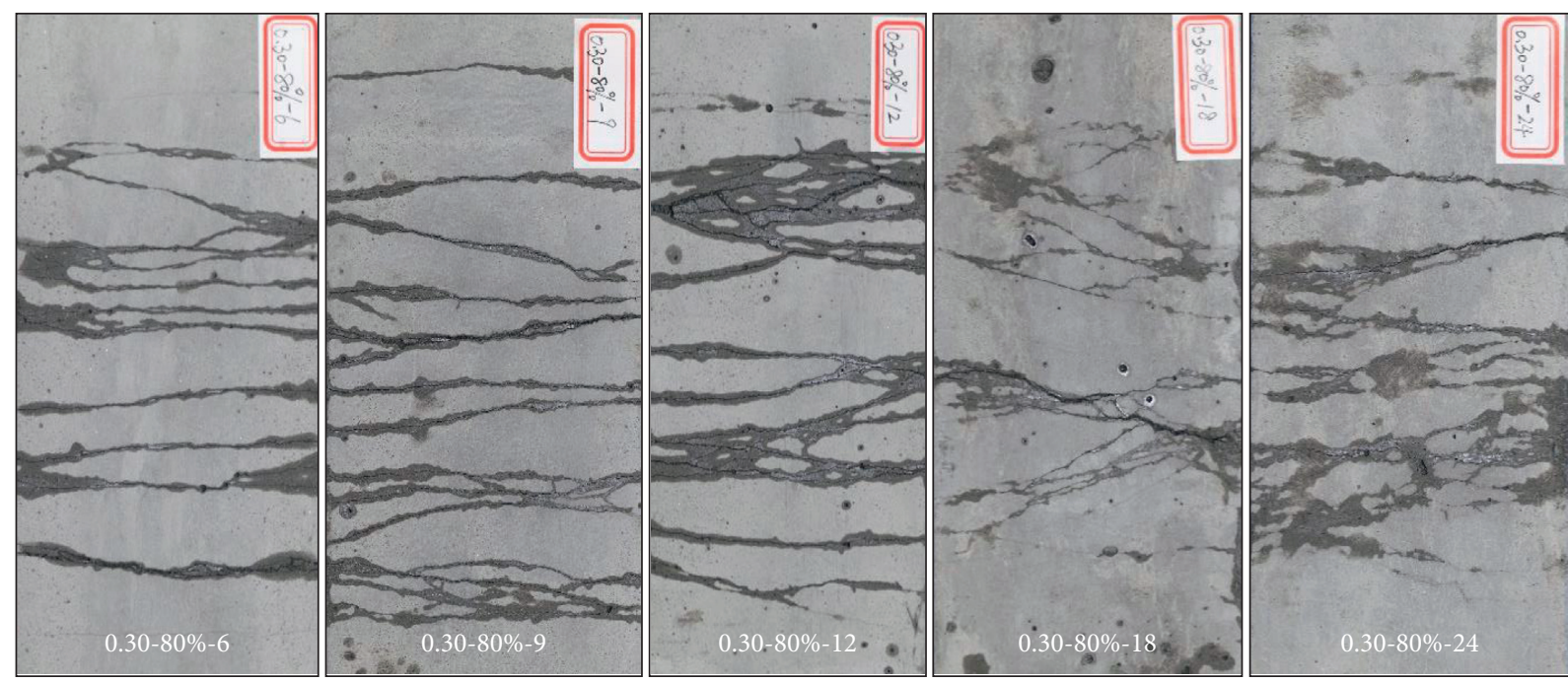

(a)

FIgURE 16: Continued. 

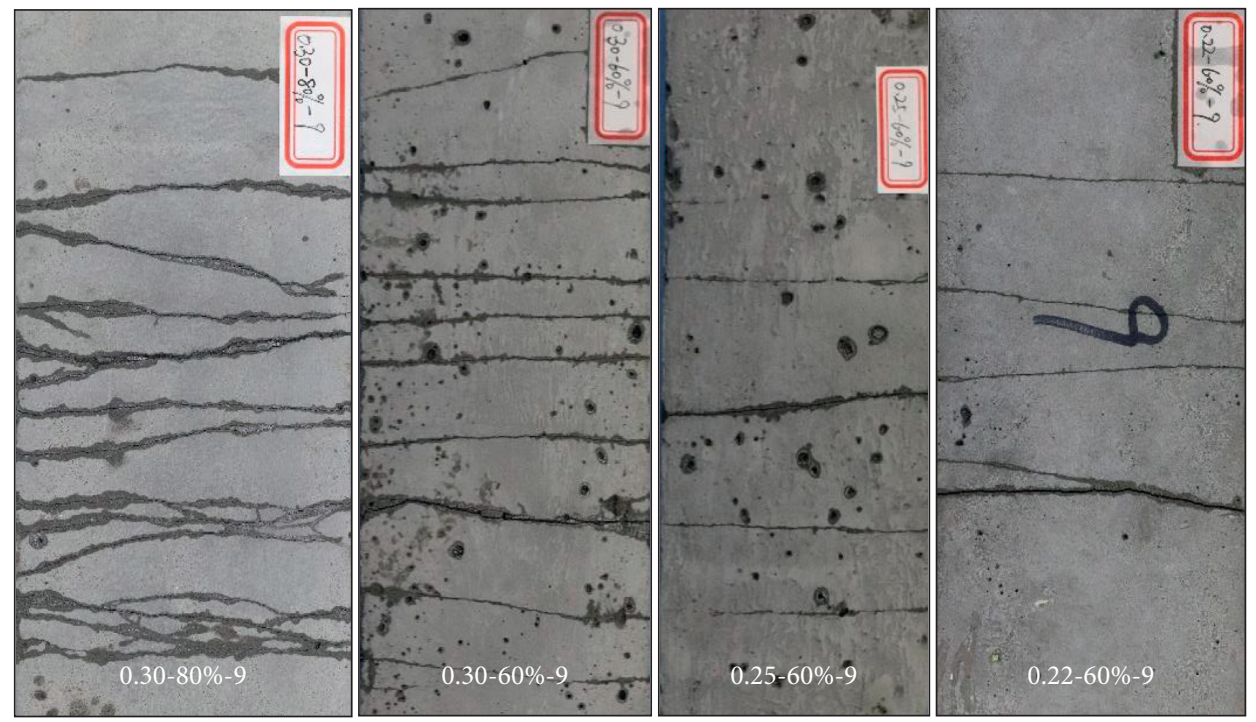

(b)

FIGURE 16: Cracking pattern of HDCCs in the pure bending region under four-point flexural stress. (a) HDCCs with the same mix proportions and different fiber lengths. (b) HDCCs with different strength grades and the same lengths for the PVA fibers.

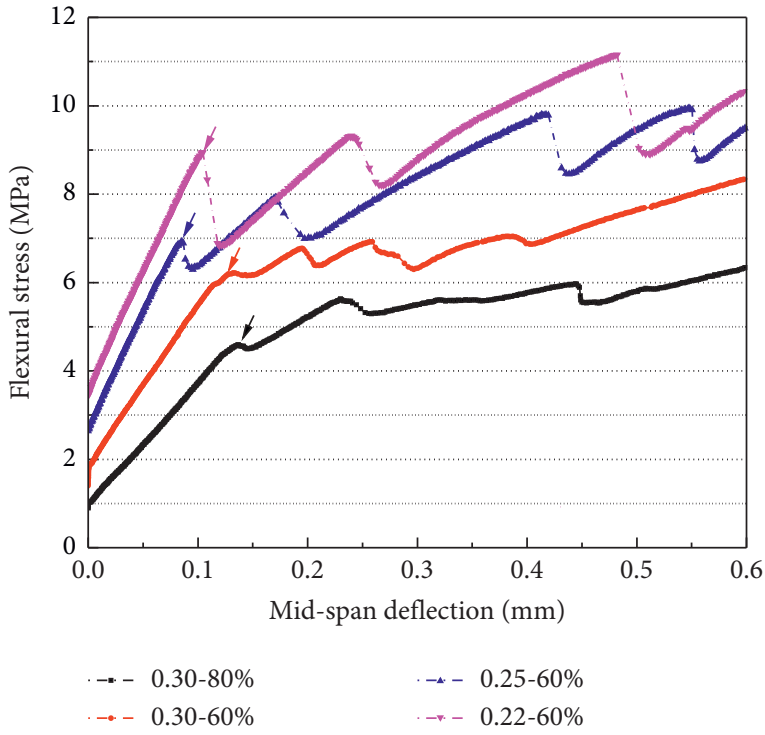

(a)

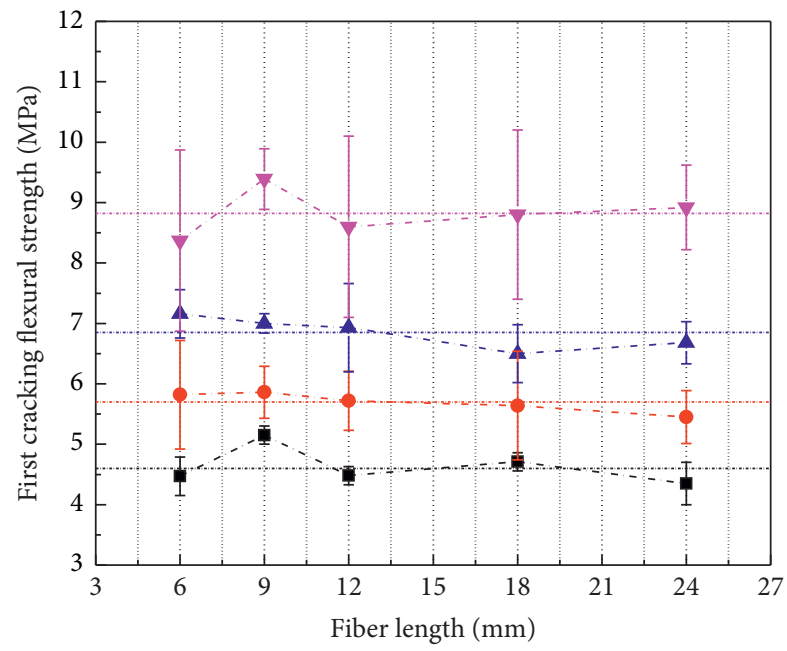

$-0.30-80 \%$

- $-0.30-60 \%$ $\rightarrow-0.25-60 \%$

(b)

FIGURE 17: Initial cracking properties of HDCCs with different PVA fiber lengths. (a) Initial stress-deflection curves at the initial cracking point. (b) Effect of the fiber length on the initial cracking flexural strength.

easy to understand. However, the longer fibers $(18 \mathrm{~mm}$ and $24 \mathrm{~mm}$ ) exhibited twining phenomena and poor dispersion, and the effective content of fibers were less than $2.0 \%$, as can be found in Figure 10. In addition, previous results [45] also showed that the fiber dispersion decreased linearly with the increase of fiber length. Thus, HDCCs with $18 \mathrm{~mm}$ fibers or $24 \mathrm{~mm}$ fibers achieve weaker flexural properties than those of other lengths, although they experience a high fiber bridging stress $\sigma_{0}$ and complementary energy $J_{b}^{\prime}$ in theory. In practice, the uneven distribution of longer fibers $(18 \mathrm{~mm}$ and $24 \mathrm{~mm}$ ) reduced the bridging capacity of fibers, and the actual bridging capacity was even lower than that of $9 \mathrm{~mm}$ and $12 \mathrm{~mm}$ fibers. Therefore, the experimental results were predictable, and moderate length of PVA fiber $(9 \mathrm{~mm}$ and $12 \mathrm{~mm}$ ) brought about better flexural strength and deformation capacity than shorter $(6 \mathrm{~mm})$ and longer (18 $\mathrm{mm}$ and $24 \mathrm{~mm})$ fibers.

The cracking pattern intuitively shows the differences in the performance for fibers with different lengths, as shown in Figure 16. For the $0.30-80 \%$ series, $0.30-80 \%-9$ and 0.30-80\%-12 formed 17 and 18 cracks, respectively. The 


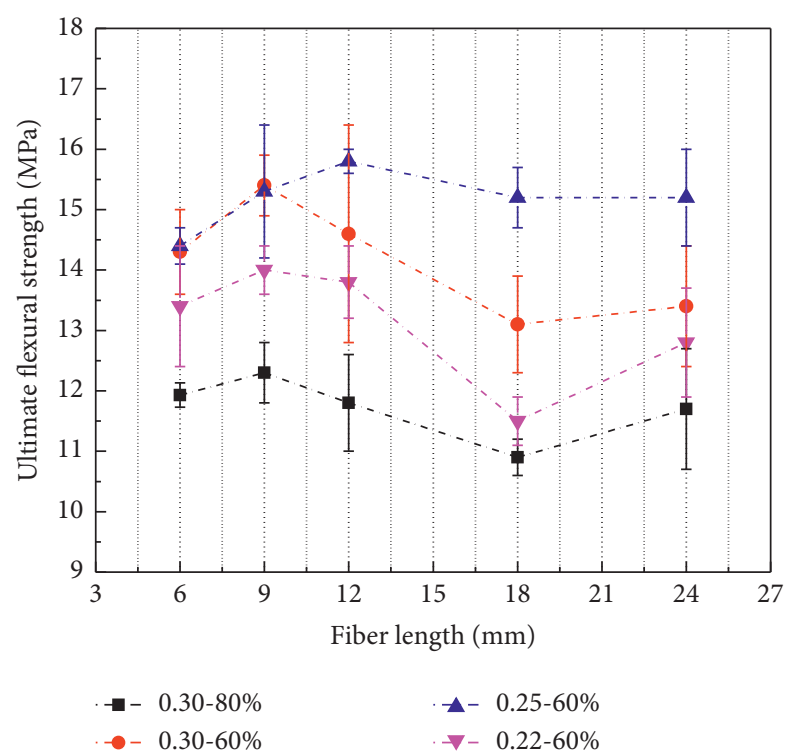

(a)

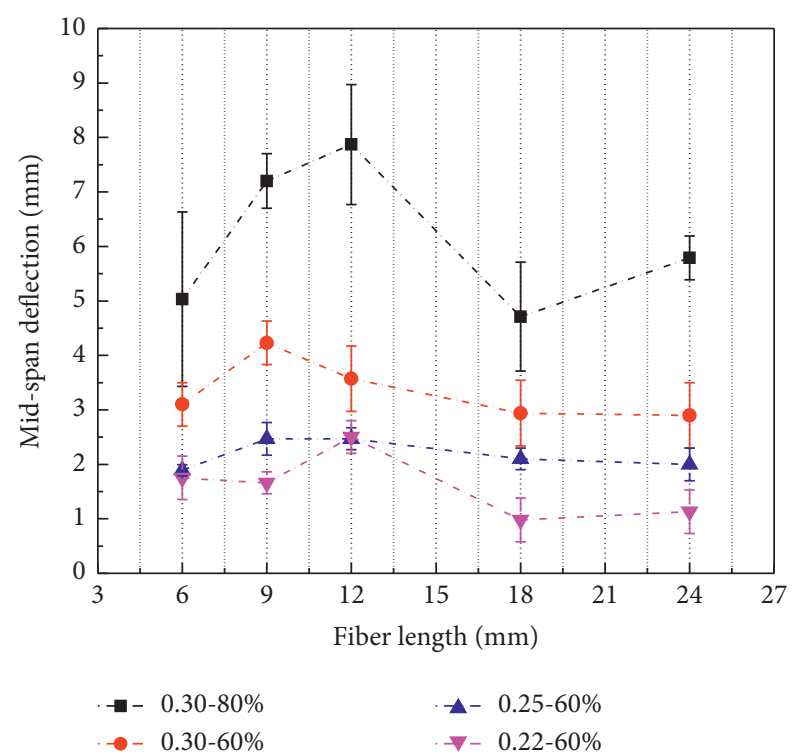

(b)

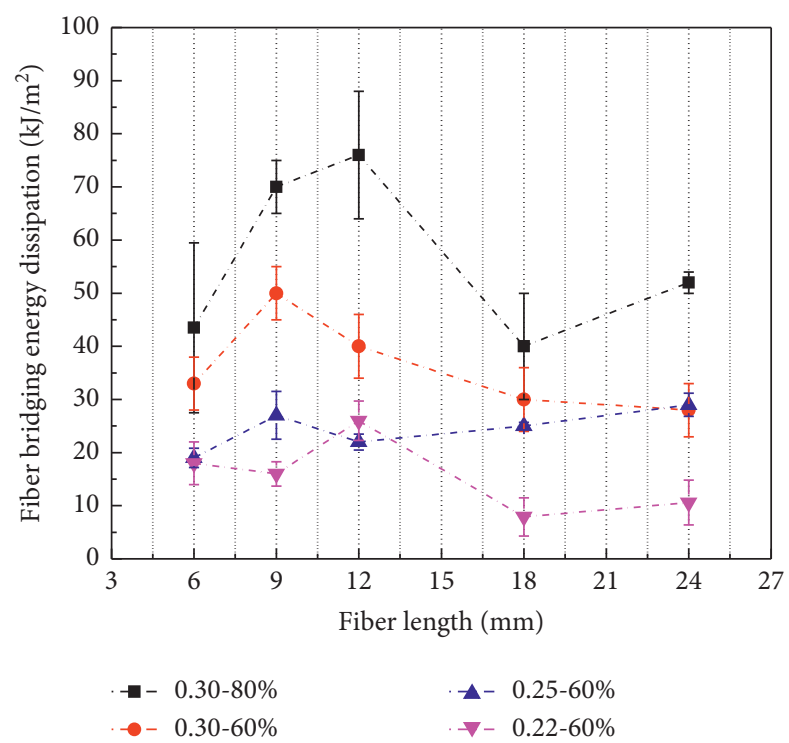

(c)

Figure 18: Effect of the fiber lengths on the flexural properties of HDCCs. (a) Ultimate flexural strength. (b) Midspan deflection. (c) Energy dissipation due to fiber bridging.

$0.30-80 \%-6, \quad 0.30-80 \%-18$, and $0.30-80 \%-24$ samples showed fewer cracks with 11,12 , and 14 cracks, respectively. Regardless of the matrix properties, the $9 \mathrm{~mm}$ fibers and $12 \mathrm{~mm}$ fibers are all the better candidates, and the matrix properties for the two lengths depend on the quality control of preparation procedure.

4.3. Uniaxial Tensile Properties. Based on the flexural properties, $9 \mathrm{~mm}$ and $12 \mathrm{~mm}$ PVA fibers were preferable candidates. Extremely longer fibers will tend to twine and are hard to disperse evenly, and inferior tensile properties will be expected. Therefore, uniaxial tensile tests were conducted only for the HDCCs with fibers with lengths of $9 \mathrm{~mm}$ and $12 \mathrm{~mm}$ in this part.
The curves of the uniaxial tensile stress versus strain are shown in Figure 19. The ultimate tensile stress and tensile ductility are presented in Figure 20 and Table 4 . As shown in Figure 19, all the HDCCs specimens exhibited tensile strain hardening characteristics, and the bridging stress of the $9 \mathrm{~mm}$ fibers and the $12 \mathrm{~mm}$ fibers all exceeded the matrix first cracking strength. For each mixture, the tensile properties affected by the fiber length were different. In general, the HDCCs with $9 \mathrm{~mm}$ fibers exhibited better tensile ductility, and the tensile strengths were slightly lower except for that of the $0.22-60 \%$ series.

For the $0.30-80 \%$ series, $9 \mathrm{~mm}$ fibers and $12 \mathrm{~mm}$ fibers made the HDCCs exhibit the same level of tensile properties. The ultimate tensile strength of the $0.30-80 \%-9$ specimen 


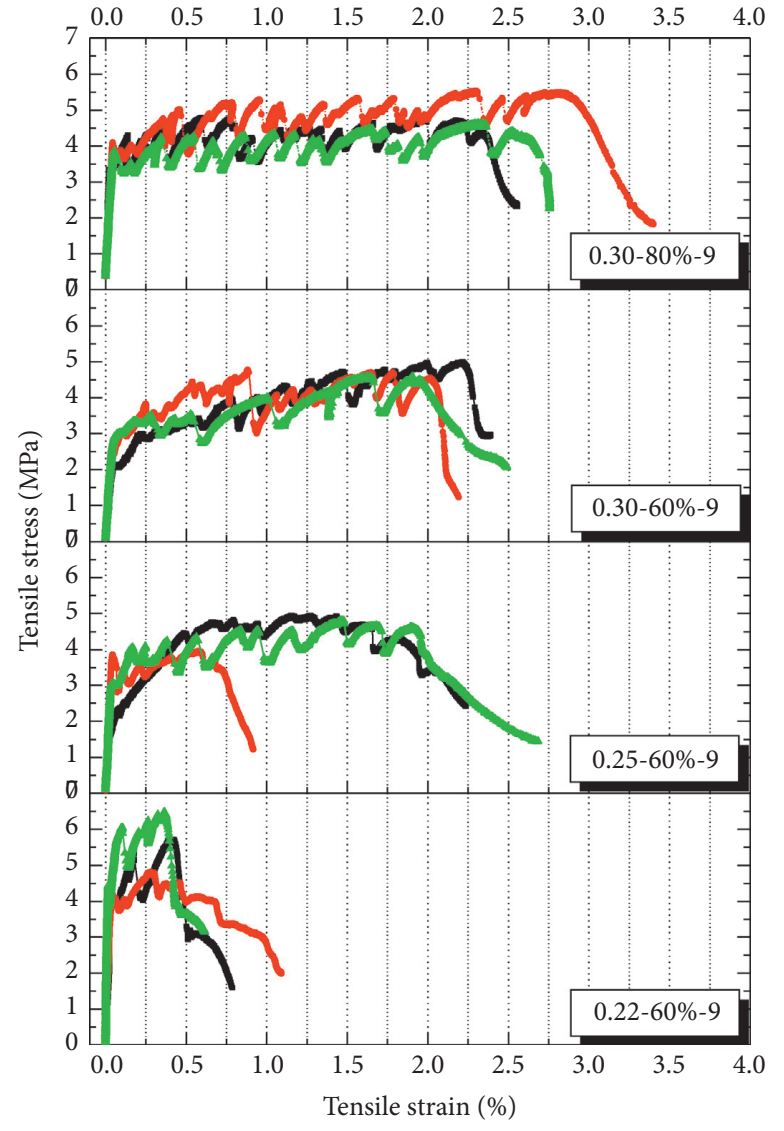

(a)

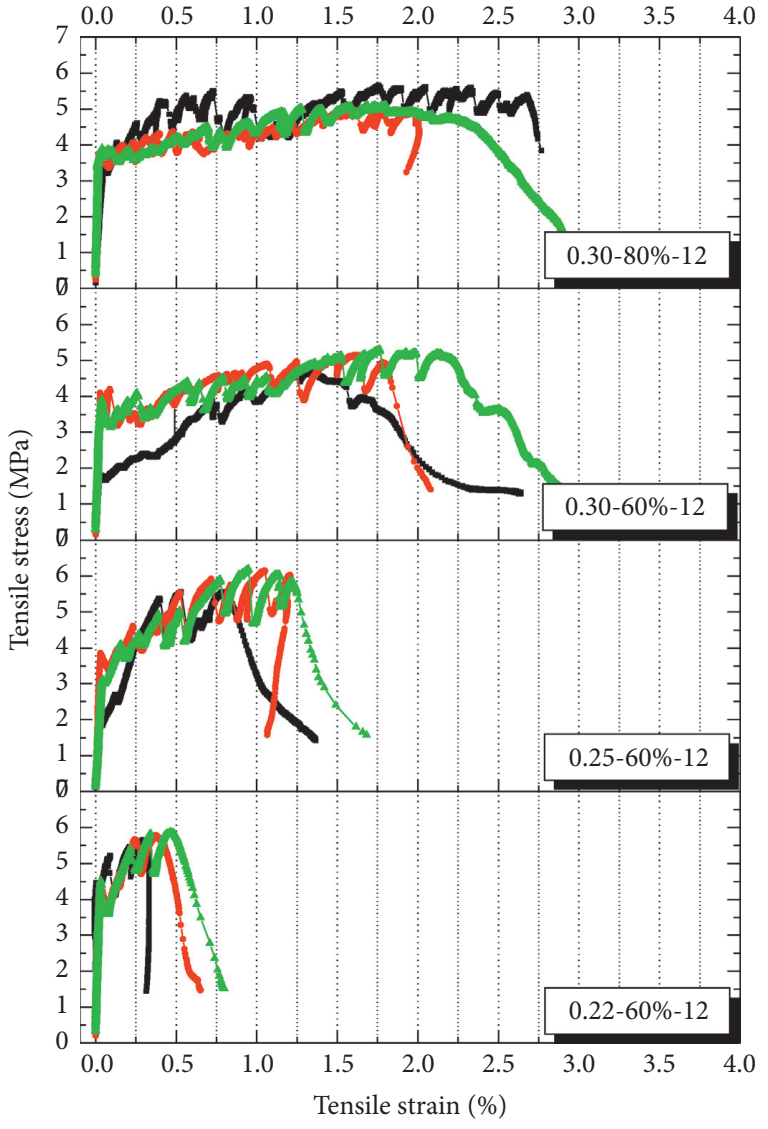

(b)

FIGURE 19: Uniaxial tensile stress versus strain curves of HDCCs with different lengths of PVA fibers. $(\mathrm{a}) L_{f}=9 \mathrm{~mm}$. (b) $L_{f}=12 \mathrm{~mm}$.

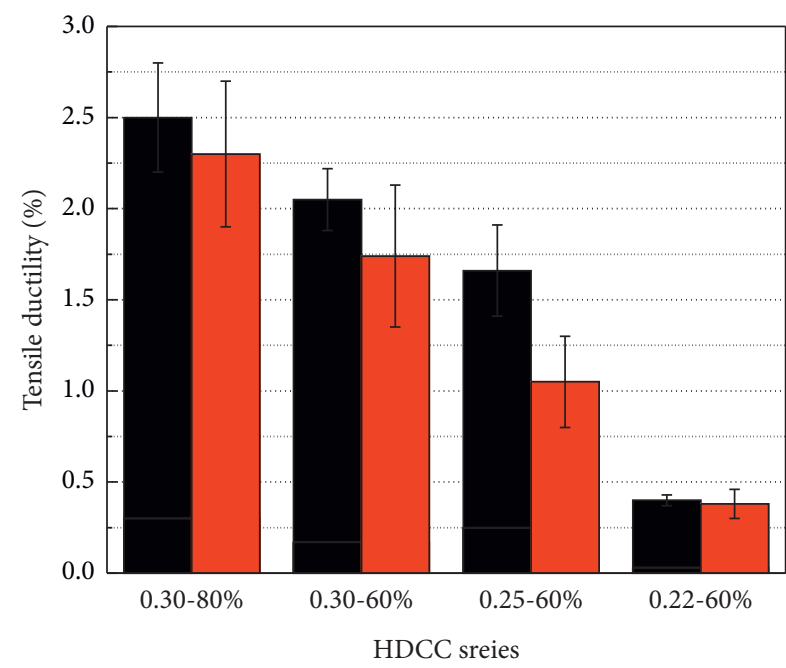

$\mathrm{L}_{\mathrm{f}}=9 \mathrm{~mm}$
$\mathrm{~L}_{\mathrm{f}}=12 \mathrm{~mm}$

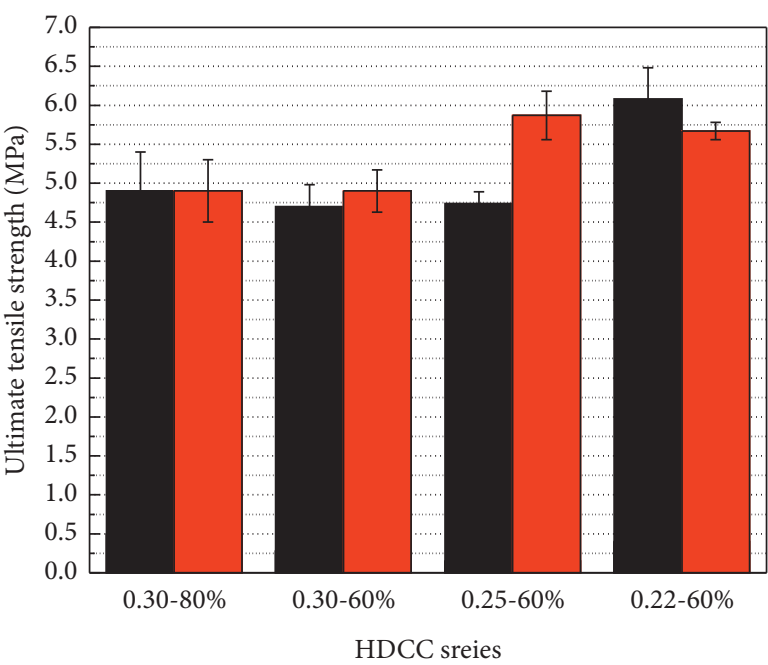

$\mathrm{L}_{\mathrm{f}}=9 \mathrm{~mm}$
$\mathrm{~L}_{\mathrm{f}}=12 \mathrm{~mm}$

(a)

(b)

Figure 20: Ultimate tensile properties of HDCCs with different lengths of PVA fibers. (a) Tensile ductility. (b) Ultimate tensile strength. 
reached 4.91 MPa accompanied by a tensile ductility of $2.5 \%$, and the $0.30-80 \%-12$ specimen achieved an ultimate tensile strength of $4.62 \mathrm{MPa}$ and a slightly lower tensile ductility of 2.34\%.

For the $0.30-60 \%$ and $0.25-60 \%$ series, the HDCCs with $9 \mathrm{~mm}$ fibers achieved tensile ductility values of $2.05 \%$ and $1.67 \%$, respectively, which were $117.8 \%$ and $159.0 \%$ higher than that of the samples with $12 \mathrm{~mm}$ long fibers. However, HDCCs with $12 \mathrm{~mm}$ fibers can achieve higher ultimate tensile strengths of $4.91 \mathrm{MPa}$ and $5.87 \mathrm{MPa}$, which were $4.7 \%$ and $23.8 \%$ higher than those of the $9 \mathrm{~mm}$ fibers.

Inferior tensile ductility can be found in the $0.22-60 \%$ series regardless of whether the contents of the fibers with lengths of $9 \mathrm{~mm}$ or $12 \mathrm{~mm}$ were all less than $0.5 \%$. Nevertheless, tensile strain hardening behaviour still appeared. The tensile ductility values of the $0.22-60 \%-9$ and 0.22-60\%-12 samples were almost the same and were $0.40 \%$ and $0.39 \%$, respectively. In addition, the former exhibited a higher ultimate tensile strength of $6.08 \mathrm{MPa}$, which was $7.2 \%$ higher than the latter. Although $12 \mathrm{~mm}$ fibers have a stronger bridging capacity based on micromechanical analysis, the HDCCs with $9 \mathrm{~mm}$ fibers achieved better or similar tensile ductility results. It can be concluded that the fiber distribution has a great influence on the tensile properties [47-49].

Although $12 \mathrm{~mm}$ fibers can achieve stronger bridging capacity, the tensile properties of HDCCs prepared by $12 \mathrm{~mm}$ fibers are not completely dominant. According to previous research results [45], shorter fibers can achieve better dispersion, while longer fibers are difficult to disperse evenly. From the results of uniaxial tensile properties, it can be inferred that the fiber dispersion has a significant effect on tensile properties and sometimes even exceeds the influence of fiber bridging capacity. For example, in Zhou's study [47], the tensile ductility of HDCCs reached $1.5 \%$ when the fiber dispersion coefficient is 0.72 , while the tensile ductility of HDCCs reached $2.5 \%$ when the fiber dispersion coefficient is 0.72 increased to 0.78 . The tensile ductility of HDCCs was significantly increased by $66.7 \%$ with the increase of fiber dispersion coefficient by $8.3 \%$. Similar results can also be found in the studies of Torigoe [48] and Felekoglu [49]. For HDCCs with different strength, the tensile properties showed similar effects. Due to the significant influence of fiber dispersion, thus it is recommended to select $9 \mathrm{~mm}$ fiber because it is easier to be evenly dispersed in the preparation of HDCCs.

Combined with the results of the tensile properties and flexural properties, for the HDCCs with compressive strength grades from $30 \mathrm{MPa}$ to $80 \mathrm{MPa}$, the $9 \mathrm{~mm}$ fibers appear to be a better candidate. On the one hand, the $9 \mathrm{~mm}$ fibers can be easily dispersed; on the other hand, the HDCCs with $9 \mathrm{~mm}$ fibers achieved a balance in mechanical performance and workability.

\section{Conclusions}

The fiber length has a profound impact on the fiber bridging capacity and the mechanical performance of composites. To tailor the optimum fiber length for HDCCs, first, this study theoretically explored the effect of the fiber length on the bridging stress $\sigma_{0}$ and complementary energy $J_{b}^{\prime}$ with various fiber/matrix interfacial bonds $\tau_{0}$. Then, a series of experiments, including compressive tests, fourpoint flexural tests, and uniaxial tensile tests, were conducted, and five kinds of fiber lengths and four kinds of HDCCs mixtures were employed. The following conclusions can be drawn based on theoretical and experimental investigations:

(1) Theoretical analysis indicates that longer fibers can achieve a stronger bridging stress $\sigma_{0}$ and sufficient complementary energy $J_{b}^{\prime}$ even if fiber rupture occurs. However, the increase in bridging stress $\sigma_{0}$ and complementary energy $J_{b}^{\prime}$ are actually very slow when the fiber length exceeds $12 \mathrm{~mm}$. With the increase in the interfacial bonding stress $\tau_{0}$, the bridging stress $\sigma_{0}$ was enhanced for the fibers with lengths that ranged from $6 \mathrm{~mm}$ to $24 \mathrm{~mm}$, while the complementary energy $J_{b}^{\prime}$ first increased and then decreased for the $6 \mathrm{~mm}, 9 \mathrm{~mm}$, and $12 \mathrm{~mm}$ fibers and continued to decrease for the $18 \mathrm{~mm}$ and $24 \mathrm{~mm}$ fibers.

(2) For the HDCCs with compressive strength grades from $30 \mathrm{MPa}$ to $80 \mathrm{MPa}$, the compressive properties are less affected by the fiber length. By incorporating PVA fibers, the compressive strengths were enhanced for the $0.30-80 \%, 0.30-60 \%$, and $0.25-60 \%$ series regardless of the fiber length. However, a decreasing tendency was exhibited for the $0.22-60 \%$ series.

(3) The HDCCs with different fiber lengths have similar initial cracking strengths, although there are fluctuations. The effect of the fiber bridging capacity on the flexural properties is mainly reflected in the postcracking stage. The HDCCs with $9 \mathrm{~mm}$ fibers or $12 \mathrm{~mm}$ fibers generally achieved higher ultimate flexural strength and larger midspan deflection regardless of matrix strength, and shorter or longer fibers made the HDCCs exhibit slightly weaker flexural properties. In addition, compared with $12 \mathrm{~mm}$ fibers, $9 \mathrm{~mm}$ fibers resulted in better tensile ductility, and the tensile strengths were slightly lower except for the $0.22-60 \%$ series.

(4) Considering the fiber dispersion, HDCCs workability, and mechanical properties, the $9 \mathrm{~mm}$ fiber is considered to be the appropriate fiber length for HDCCs with compressive strength grades that range from $30 \mathrm{MPa}$ to $80 \mathrm{MPa}$.

\section{Data Availability}

The data used to support the findings of this study are available from the corresponding author upon request.

\section{Conflicts of Interest}

The authors declare that they have no conflicts of interest. 


\section{Acknowledgments}

This work was mainly supported by the National Natural Science Foundations of China (Grant nos. 51778133 and 51739008).

\section{References}

[1] C. Ding, L. Guo, B. Chen, Y. Xu, Y. Cao, and C. Fei, "Micromechanics theory guidelines and method exploration for surface treatment of PVA fibers used in high-ductility cementitious composites," Construction and Building Materials, vol. 196, pp. 154-165, 2019.

[2] O. Ozturk, G. Yildirim, U. S. Keskin, H. Siad, and M. Sahmaran, "Nano-tailored multi-functional cementitious composites," Composites Part B: Engineering, vol. 182, Article ID 107670, 2019.

[3] A. Alyousif, M. Lachemi, G. Yildirim, G. H. Aras, and M. Sahmaran, "Influence of cyclic frost deterioration on water sorptivity of microcracked cementitious composites," Journal of Materials in Civil Engineering, vol. 28, no. 4, Article ID 04015159, 2016.

[4] M. Sahmaran, G. Yildirim, E. Ozbay, K. Ahmed, and M. Lachemi, "Self-healing ability of cementitious composites: effect of addition of pre-soaked expanded perlite," Magazine of Concrete Research, vol. 66, pp. 409-419, 2014.

[5] M. Sahmaran, M. Al-Emam, G. Yildirim, Y. E. Semsek, T. K. Erdem, and M. Lachemi, "High-early-strength ductile cementitious composites with characteristics of low early-age shrinkage for repair of infrastructures," Materials and Structures, vol. 48, pp. 1389-1403, 2015.

[6] C. Lu, V. C. Li, and C. K. Y. Leung, "Flaw characterization and correlation with cracking strength in Engineered Cementitious Composites (ECC)," Cement and Concrete Research, vol. 107, pp. 64-74, 2018.

[7] J. Yu, Y. Chen, and C. K. Y. Leung, "Micromechanical modeling of crack-bridging relations of hybrid-fiber strainhardening cementitious composites considering interaction between different fibers," Construction and Building Materials, vol. 182, pp. 629-636, 2018.

[8] M. Ranjbarian, V. Mechtcherine, Z. Zhang, I. Curosu, J. Storm, and M. Kaliske, "Locking Front Model for pull-out behaviour of PVA microfibre embedded in cementitious matrix," Cement and Concrete Composites, vol. 103, pp. 318-330, 2019.

[9] V. Afroughsabet, G. Geng, A. Lin, and P. J. M. Monteiro, "The influence of expansive cement on the mechanical, physical, and microstructural properties of hybrid-fiber-reinforced concrete," Cement and Concrete Composites, vol. 96, pp. 2132,2018

[10] H. Ma, S. Qian, and V. C. Li, "Tailoring engineered cementitious composite with emulsified asphalt for high damping," Construction and Building Materials, vol. 201, pp. 631-640, 2019.

[11] S. Gao, Z. Wang, W. Wang, and H. Qiu, "Effect of shrinkagereducing admixture and expansive agent on mechanical properties and drying shrinkage of engineered cementitious composite (ECC)," Construction and Building Materials, vol. 179, pp. 172-185, 2018.

[12] V. C. Li, Y. Wang, and S. Backer, "A micromechanical model of tension-softening and bridging toughening of short random fiber reinforced brittle matrix composites," Journal of the Mechanics and Physics of Solids, vol. 39, no. 5, pp. 607-625, 1991.
[13] Z. Lin, T. Kanda, and V. C. Li, "On interface property characterization and performance of fiber reinforced cementitious composites," Concr. Sci. Eng.vol. 1, pp. 173-184, 1999.

[14] M. Maalej, V. C. Li, and T. Hashida, "Effect of fiber rupture on tensile properties of short fiber composites," Journal of Engineering Mechanics, vol. 121, no. 8, pp. 903-913, 1995.

[15] V. C. Li and K. Obla, "Effect of fiber diameter variation on properties of cement-based matrix fiber reinforced composites," Composites Part B: Engineering, vol. 27, no. 3-4, pp. 275-284, 1996.

[16] X.-R. Cai, S.-L. Xu, and B.-Q. Fu, "A statistical micromechanical model of multiple cracking for ultra high toughness cementitious composites," Engineering Fracture Mechanics, vol. 78, no. 6, pp. 1091-1100, 2011.

[17] H. Li and S. Xu, "Determination of energy consumption in the fracture plane of ultra high toughness cementitious composite with direct tension test," Engineering Fracture Mechanics, vol. 78, no. 9, pp. 1895-1905, 2011.

[18] M. A. Etminani and F. Sharif, "Effect of fiber nano-scratch on macro strain hardening behavior in engineered cementitious composites," Physica B: Condensed Matter, vol. 545, pp. 442-451, 2018.

[19] W. Liu, S. Xu, and Q. Li, "Experimental study on fracture performance of ultra-high toughness cementitious composites with J-integral," Engineering Fracture Mechanics, vol. 96, pp. 656-666, 2012.

[20] J. Yu, Y. Chen, and C. K. Y. Leung, "Mechanical performance of strain-hardening cementitious composites (SHCC) with hybrid polyvinyl alcohol and steel fibers," Composite Structures, vol. 226, Article ID 111198, 2019.

[21] B. Nematollahi, J. Qiu, E.-H. Yang, and J. Sanjayan, "Micromechanics constitutive modelling and optimization of strain hardening geopolymer composite," Ceramics International, vol. 43, no. 8, pp. 5999-6007, 2017.

[22] S. F. U. Ahmed and H. Mihashi, "Strain hardening behavior of lightweight hybrid polyvinyl alcohol (PVA) fiber reinforced cement composites," Materials and Structures, vol. 44, no. 6, pp. 1179-1191, 2011.

[23] M. H. Al-Majidi, A. Lampropoulos, and A. B. Cundy, "Tensile properties of a novel fibre reinforced geopolymer composite with enhanced strain hardening characteristics," Composite Structures, vol. 168, pp. 402-427, 2017.

[24] J. Trejbal, V. Nežerka, M. Somr et al., "Deterioration of bonding capacity of plasma-treated polymer fiber reinforcement," Cement and Concrete Composites, vol. 89, pp. 205-215, 2018.

[25] J. Li and E.-H. Yang, "Probabilistic-based assessment for tensile strain-hardening potential of fiber-reinforced cementitious composites," Cement and Concrete Composites, vol. 91, pp. 108-117, 2018.

[26] H. R. Pakravan, M. Jamshidi, and M. Latifi, "Study on fiber hybridization effect of engineered cementitious composites with low- and high-modulus polymeric fibers," Construction and Building Materials, vol. 112, pp. 739-746, 2016.

[27] T. Kanda and V. C. Li, "New micromechanics design theory for pseudostrain hardening cementitious composite," Journal of Engineering Mechanics, vol. 125, no. 4, pp. 373-381, 1999.

[28] L. R. Betterman, C. Ouyang, and S. P. Shah, "Fiber-matrix interaction in microfiber-reinforced mortar," Advanced Cement Based Materials, vol. 2, no. 2, pp. 53-61, 1995.

[29] C. Lu and C. K. Y. Leung, "A new model for the cracking process and tensile ductility of strain hardening cementitious 
composites (SHCC)," Cement and Concrete Research, vol. 79, pp. 353-365, 2016.

[30] A. V. Georgiou and S. J. Pantazopoulou, "Effect of fiber length and surface characteristics on the mechanical properties of cementitious composites," Construction and Building Materials, vol. 125, pp. 1216-1228, 2016.

[31] S. Sasmal and G. Avinash, "Investigations on mechanical performance of cementitious composites micro-engineered with poly vinyl alcohol fibers," Construction and Building Materials, vol. 128, pp. 136-147, 2016.

[32] B.-T. Huang, J.-Q. Wu, J. Yu, J.-G. Dai, C. K. Y. Leung, and V. C. Li, "Seawater sea-sand engineered/strain-hardening cementitious composites (ECC/SHCC): assessment and modeling of crack characteristics," Cement and Concrete Research, vol. 140, Article ID 106292, 2021.

[33] G. Xue, E. Yilmaz, W. Song, and S. Cao, "Fiber length effect on strength properties of polypropylene fiber reinforced cemented tailings backfill specimens with different sizes," Construction and Building Materials, vol. 241, Article ID 118113, 2020.

[34] V. C. Li, "From micromechanics to structural engineering-the design of cementitious composites for civil engineering application," Journal of Structural Engineering and Earthquake Engineering, vol. 10, pp. 37-48, 1993.

[35] V. C. Li and C. K. Y. Leung, "Steady-state and multiple cracking of short random fiber composites," Journal of Engineering Mechanics, vol. 118, no. 11, pp. 2246-2264, 1992.

[36] C. K. Y. Leung, "Design criteria for pseudoductile fiberreinforced composites," Journal of Engineering Mechanics, vol. 122, no. 1, pp. 10-18, 1996.

[37] E.-H. Yang, S. Wang, Y. Yang, and V. C. Li, "Fiber-bridging constitutive law of engineered cementitious composites," Journal of Advanced Concrete Technology, vol. 6, no. 1, pp. 181-193, 2008.

[38] D. Zhang, J. Yu, H. Wu, B. Jaworska, B. R. Ellis, and V. C. Li, "Discontinuous micro-fibers as intrinsic reinforcement for ductile Engineered Cementitious Composites (ECC)," Composites Part B: Engineering, vol. 184, Article ID 107741, 2020.

[39] T. Kanda, "Multiple cracking sequence and saturation in fiber reinforced cementitious composites," Concrete Research and Technology, vol. 9, no. 2, pp. 19-33, 1998.

[40] C. Ding, L. P. Guo, and B. Chen, "Theoretical analysis on optimal fiber-matrix interfacial bonding and corresponding fiber rupture effect for high ductility cementitious composites," Construction and Building Materials, vol. 223, pp. 841-851, 2019.

[41] H. R. Pakravan and T. Ozbakkaloglu, "Synthetic fibers for cementitious composites: a critical and in-depth review of recent advances," Construction and Building Materials, vol. 207, pp. 491-518, 2019.

[42] D.-Y. Lei, L.-P. Guo, Y. Li et al., "The investigating on mechanical properties of ultra-high strength and ultra-high ductility cementitious composites (UHS-UHDCC)," Journal of Building Engineering, vol. 43, Article ID 102486, 2021.

[43] A. Noushini, B. Samali, and K. Vessalas, "Effect of polyvinyl alcohol (PVA) fibre on dynamic and material properties of fibre reinforced concrete," Construction and Building Materials, vol. 49, pp. 374-383, 2013.

[44] V. C. Li, D. K. Mishra, "Micromechanics of fiber effect on the unaxial compressive strength of cementitious composites," in Proceedings of the Fourth International Symposium Fibre Reinforced Cement and Concrete, R. N. Swamy, Ed., pp. 400-414pp. 400-, Sheffield, UK, June 1992.
[45] C. Ding, L. Guo, and B. Chen, "An optimum polyvinyl alcohol fiber length for reinforced high ductility cementitious composites based on theoretical and experimental analyses," Construction and Building Materials, vol. 259, Article ID 119824, 2020.

[46] Z. Pan, C. Wu, J. Liu, W. Wang, and J. Liu, "Study on mechanical properties of cost-effective polyvinyl alcohol engineered cementitious composites (PVA-ECC)," Construction and Building Materials, vol. 78, pp. 397-404, 2015.

[47] J. Zhou, S. Qian, G. Ye, O. Copuroglu, K. van Breugel, and V. C. Li, "Improved fiber distribution and mechanical properties of engineered cementitious composites by adjusting the mixing sequence," Cement and Concrete Composites, vol. 34, no. 3, pp. 342-348, 2012.

[48] S.-i. Torigoe, T. Horikoshi, A. Ogawa, T. Saito, and T. Hamada, "Study on evaluation method for PVA fiber distribution in engineered cementitious composite," Journal of Advanced Concrete Technology, vol. 1, no. 3, pp. 265-268, 2003.

[49] K. T. Felekoğlu, B. Felekoğlu, R. Ranade, B. Lee, and V. Li, "The role of flaw size and fiber distribution on tensile ductility of PVA-ECC," Composites Part B: Engineering, vol. 56, pp. 536-545, 2014. 